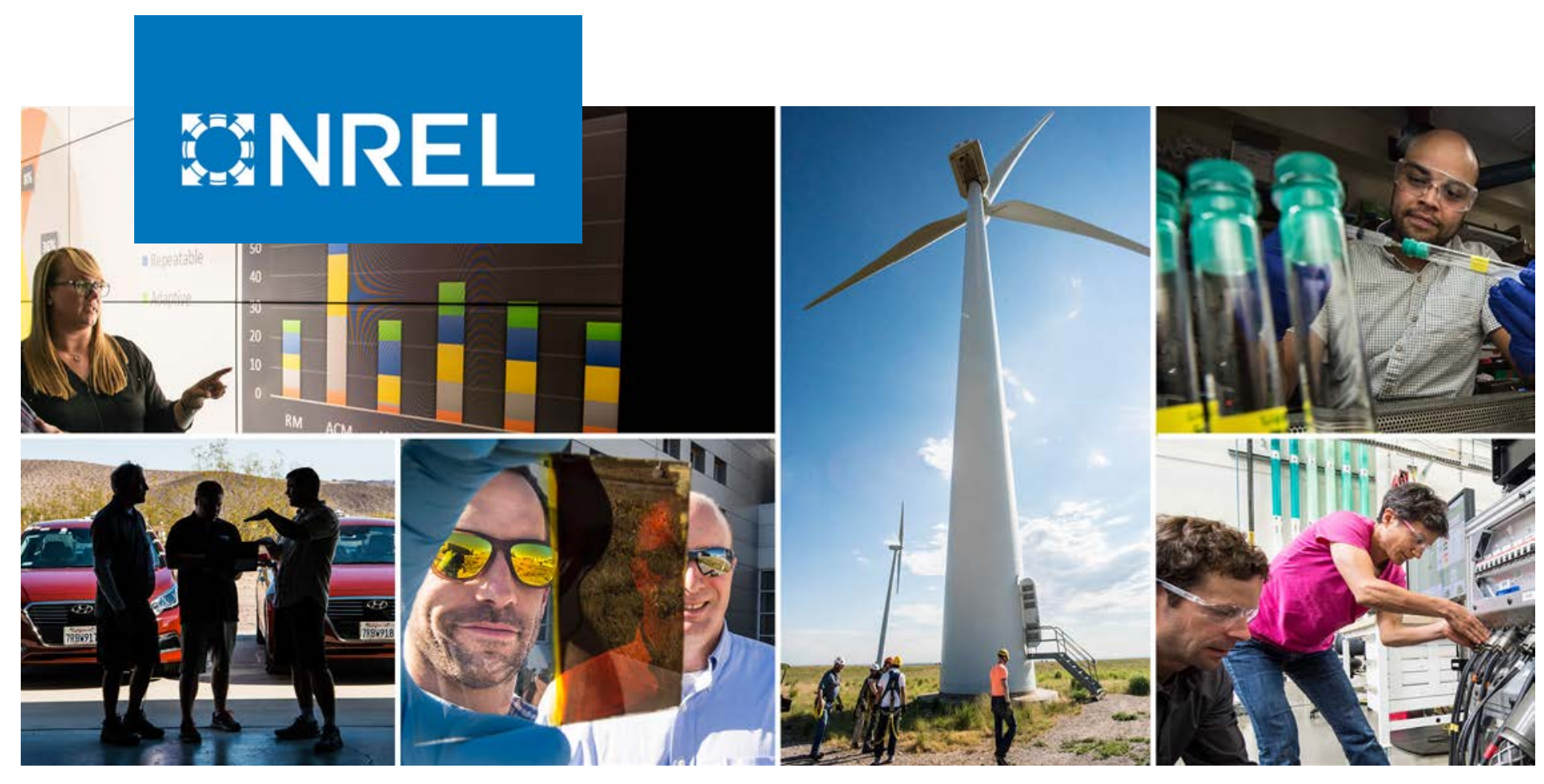

\title{
NREL's Balance-of-System Cost Model for Land-Based Wind
}

Annika Eberle, Owen Roberts, Alicia Key, Parangat Bhaskar, and Katherine Dykes

National Renewable Energy Laboratory

NREL is a national laboratory of the U.S. Department of Energy

Office of Energy Efficiency \& Renewable Energy

Operated by the Alliance for Sustainable Energy, LLC

This report is available at no cost from the National Renewable Energy Laboratory (NREL) at www.nrel.gov/publications.

\section{Technical Report}

NREL/TP-6A20-72201

September 2019 


\title{
GNREL
}

\section{NREL's Balance-of-System Cost Model for Land-Based Wind}

\author{
Annika Eberle, Owen Roberts, Alicia Key, \\ Parangat Bhaskar, and Katherine Dykes
}

National Renewable Energy Laboratory

\section{Suggested Citation}

Eberle, Annika, Owen Roberts, Alicia Key, Parangat Bhaskar, and Katherine Dykes. 2019. NREL's Balance-of-System Cost Model for Land-Based Wind. Golden, CO: National Renewable Energy Laboratory. NREL/TP-6A20-72201. https://www.nrel.gov/docs/fy19osti/72201.pdf.

NREL is a national laboratory of the U.S. Department of Energy Office of Energy Efficiency \& Renewable Energy Operated by the Alliance for Sustainable Energy, LLC

This report is available at no cost from the National Renewable Energy Laboratory (NREL) at www.nrel.gov/publications.

Contract No. DE-AC36-08GO28308
Technical Report NREL/TP-6A20-72201

September 2019

National Renewable Energy Laboratory 15013 Denver West Parkway Golden, CO 80401

303-275-3000 • www.nrel.gov 


\section{NOTICE}

This work was authored by the National Renewable Energy Laboratory, operated by Alliance for Sustainable Energy, LLC, for the U.S. Department of Energy (DOE) under Contract No. DE-AC36-08G028308. Funding provided by U.S. Department of Energy Office of Energy Efficiency and Renewable Energy Wind Energy Technologies Office. The views expressed herein do not necessarily represent the views of the DOE or the U.S. Government.

This report is available at no cost from the National Renewable Energy Laboratory (NREL) at www.nrel.gov/publications.

U.S. Department of Energy (DOE) reports produced after 1991 and a growing number of pre-1991 documents are available free via www.OSTI.gov.

Cover Photos by Dennis Schroeder: (clockwise, left to right) NREL 51934, NREL 45897, NREL 42160, NREL 45891, NREL 48097, NREL 46526.

NREL prints on paper that contains recycled content. 


\section{Acknowledgments}

This work was supported by the U.S. Department of Energy under Contract No. DE-AC3608GO28308 with Alliance for Sustainable Energy, LLC, the Manager and Operator of the National Renewable Energy Laboratory. Funding was provided by the U.S. Department of Energy Office of Energy Efficiency and Renewable Energy Wind Energy Technologies Office. We would like to thank several industry contacts at Wind Tower Technologies, Mortenson, Renewable Energy Systems, and Apex for providing helpful comments and suggestions about the model. The views and opinions of the authors expressed herein do not necessarily state or reflect those of the United States Government or any agency thereof. Neither the United States Government nor any agency thereof, nor any of their employees, makes any warranty, expressed or implied, or assumes any legal liability or responsibility for the accuracy, completeness, or usefulness of any information, apparatus, product, or process disclosed, or represents that its use would not infringe privately owned rights. 


\section{List of Acronyms}

$\begin{array}{ll}\text { BOS } & \text { balance of system } \\ \text { IEA } & \text { International Energy Agency } \\ \text { IEC } & \text { International Electrotechnical Commission } \\ \text { kV } & \text { kilovolts } \\ \text { LandBOSSE } & \text { Land-based BOS Systems Engineering model } \\ \text { LCY } & \text { loose cubic yards } \\ \text { LF } & \text { linear foot } \\ \text { m/s } & \text { meters per second } \\ \text { MW } & \text { megawatt } \\ \text { NREL } & \text { National Renewable Energy Laboratory } \\ \text { O\&M } & \text { operation and maintenance } \\ \text { OT } & \text { operation time } \\ \text { psi } & \text { pounds per square inch } \\ \text { RNA } & \text { rotor nacelle assembly } \\ \text { RSMeans } & \text { RSMeans Construction Cost Database } \\ \text { USD } & \text { U.S. dollars }\end{array}$




\section{Executive Summary}

NREL's Land-based Balance of System Systems Engineering (LandBOSSE) model is a tool for modeling the balance-of-system (BOS) costs of land-based wind plants. BOS costs currently account for approximately $30 \%$ of the capital expenditures needed to install a land-based wind plant; they include all costs associated with installing a wind plant, such as permitting, labor, material, and equipment costs associated with site preparation, foundation construction, electrical infrastructure, and tower installation.

NREL developed LandBOSSE after identifying a need for a hybrid of a process-based model and an empirically derived model that can provide flexibility for assessing wind plant BOS costs at a system level. Other NREL BOS models have relied on empirical fits of legacy industry data, which limits their predictive ability. LandBOSSE, however, was designed to help users explore tradeoffs between innovative design scenarios while balancing the level of detail and speed required for model execution. The model was developed using a hybrid of process-based and empirically derived methods to create a modular model design that will allow for updates as wind energy technologies evolves. The goal of LandBOSSE is to allow researchers, analysts, wind power developers, government agencies, and the public to explore how BOS costs may vary for different wind plant designs.

This report summarizes the approach, methods, and equations used to develop LandBOSSE Version 2.1. Future versions of the model may incorporate additional process-based capabilities or modify calculations within the code. Refer to the GitHub repository at https://github.com/WISDEM/LandBOSSE for the most up-to-date version of the software documentation and code. 


\section{Table of Contents}

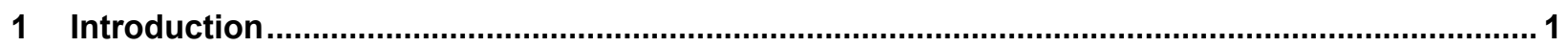

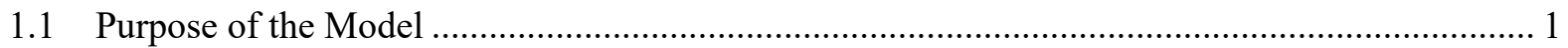

1.2 Approach to Model Development …............................................................................ 2

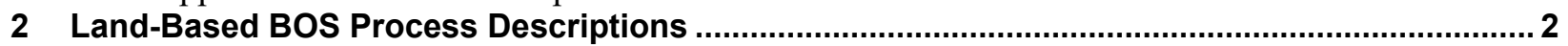

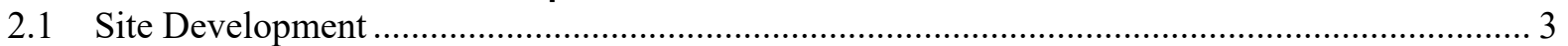

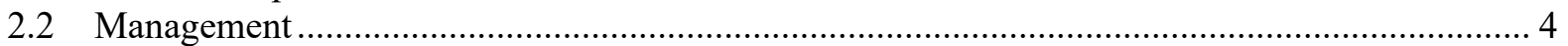

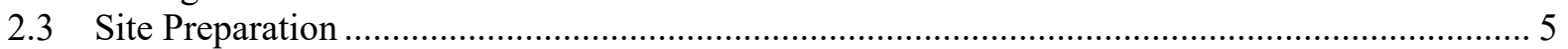

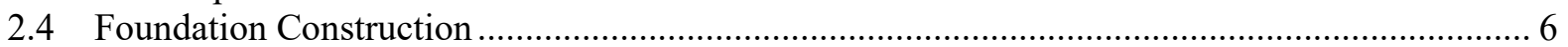

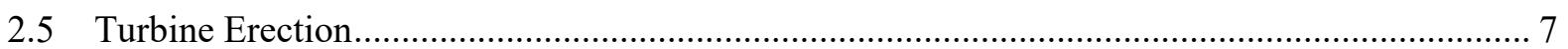

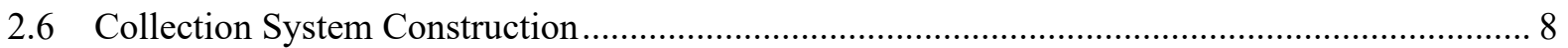

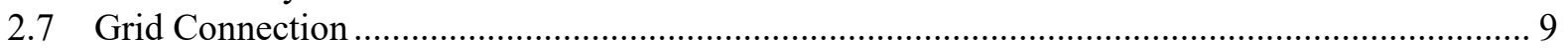

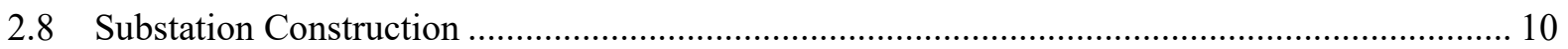

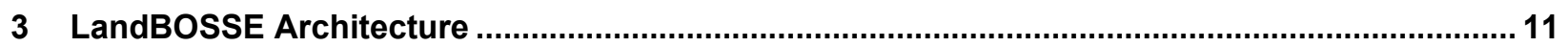

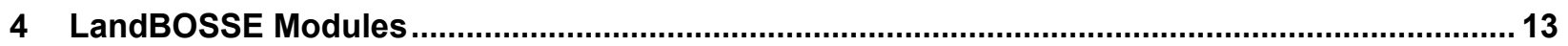

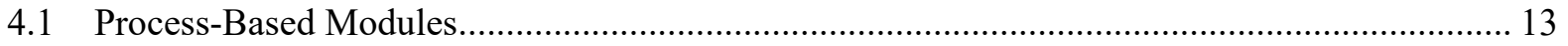

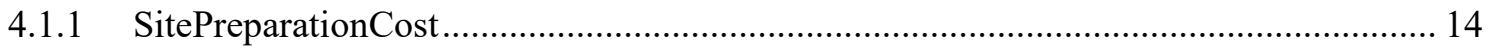

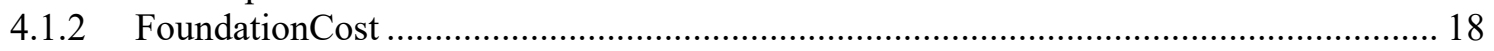

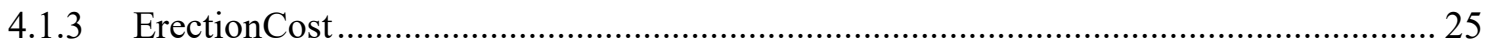

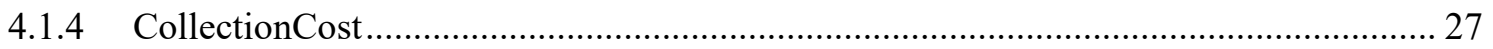

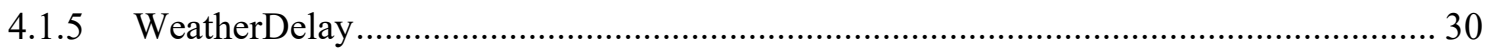

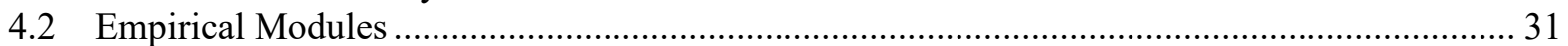

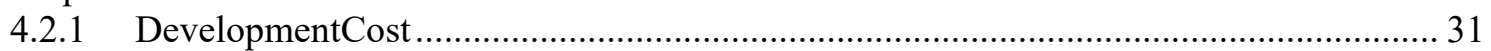

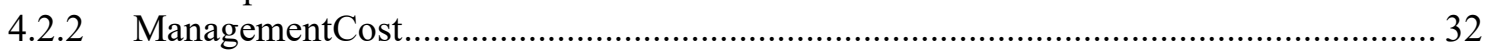

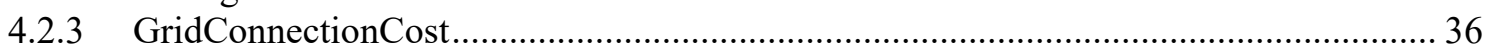

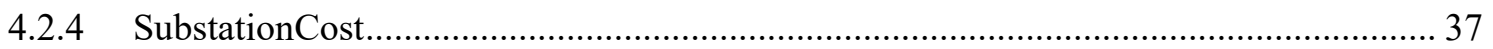

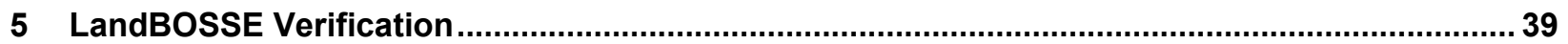

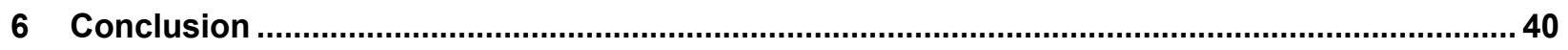

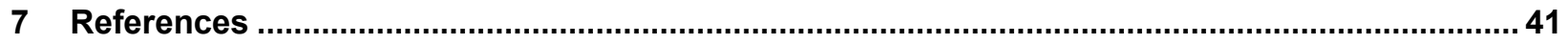

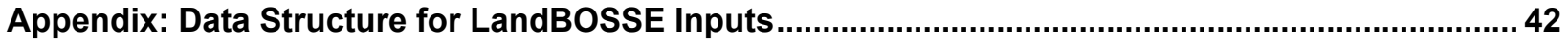

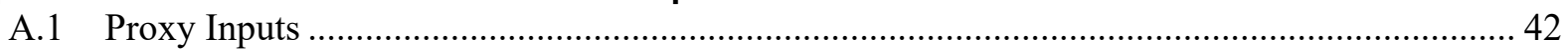

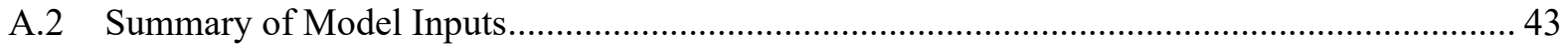

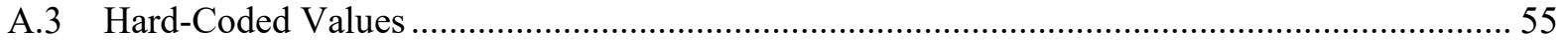




\section{List of Figures}

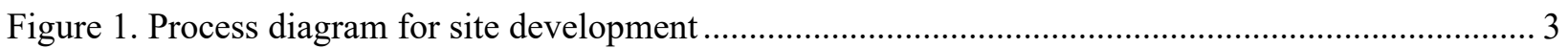

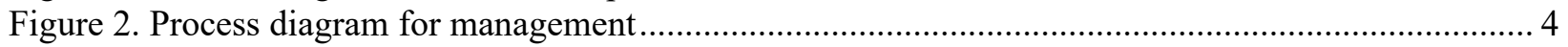

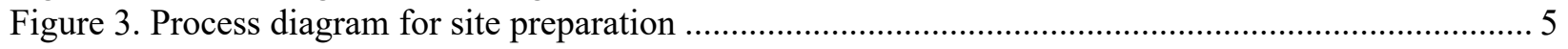

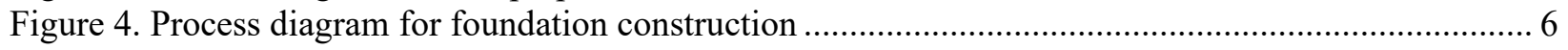

Figure 5. Process diagram for the erection of the tower and rotor nacelle assembly ................................ 7

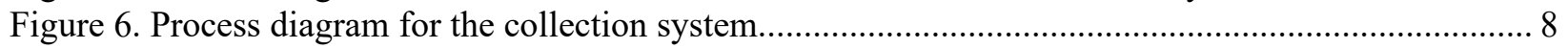

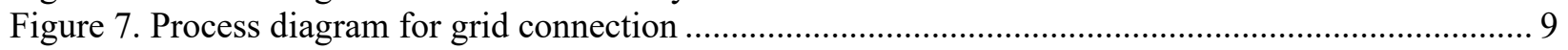

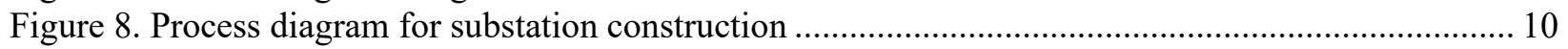

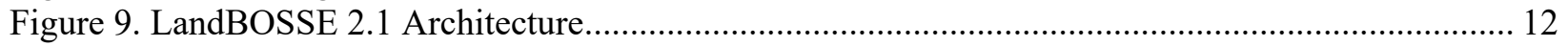

Figure 10. Implementation of SitePreparationCost module in LandBOSSE 2.1 ................................... 14

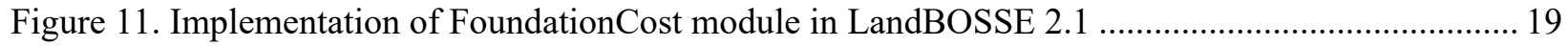

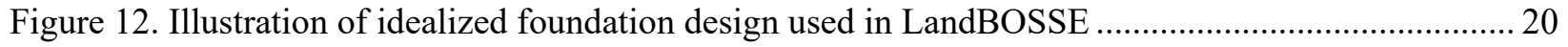

Figure 13. Implementation of ErectionCost module in LandBOSSE 2.1 ............................................2

Figure 14. Implementation of CollectionCost module in LandBOSSE 2.1 …...................................... 28

Figure 15. Sample array design used in LandBOSSE for trench length calculation ................................2 29

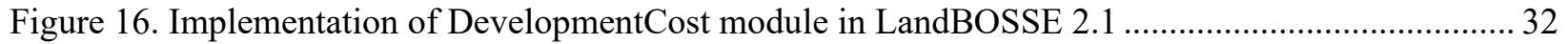

Figure 17. Implementation of ManagementCost module in LandBOSSE 2.1 ...................................... 33

Figure 18. Implementation of GridConnectionCost module in LandBOSSE 2.1 …............................... 37

Figure 19. Implementation of SubstationCost module in LandBOSSE 2.1 ........................................... 38 


\section{List of Tables}

Table 1. Implementation Method Used for Each Module in LandBOSSE 2.1 ..................................... 13

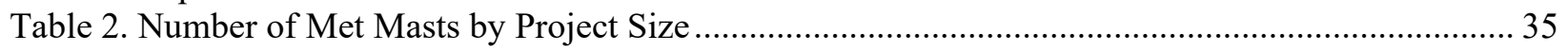

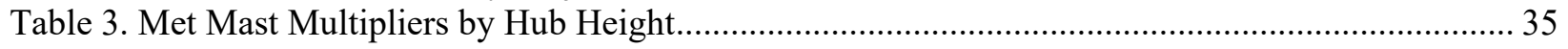

Table 4. Size of Operation and Maintenance (O\&M) Facilities by Project Size ....................................... 36

Table 5. Constants for Compound Security by Number of Turbines......................................................... 36

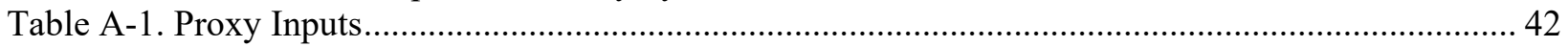

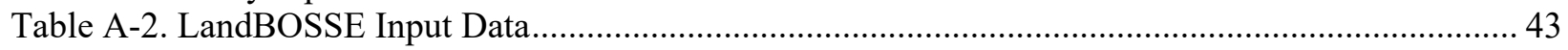

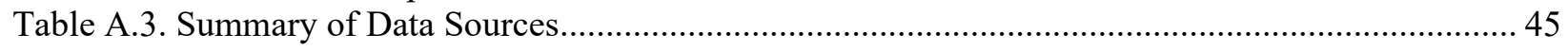

Table A-4. Sample Inputs for Project List, Listed by Project ID ........................................................ 46

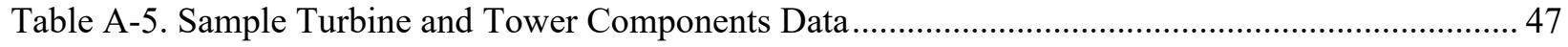

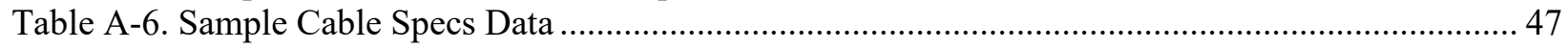

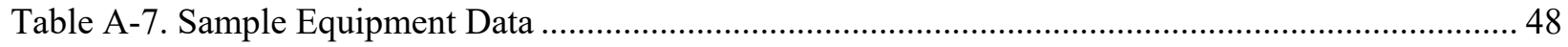

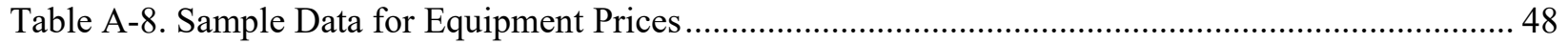

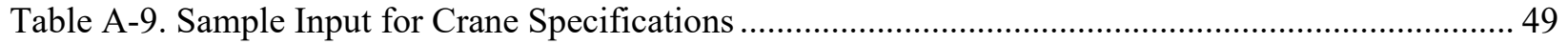

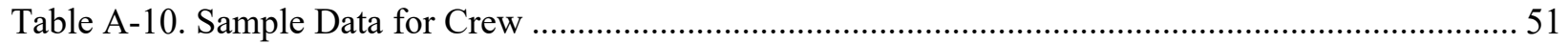

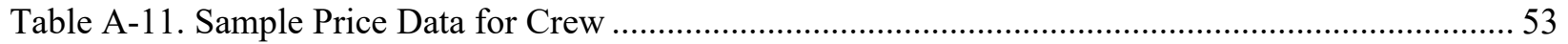

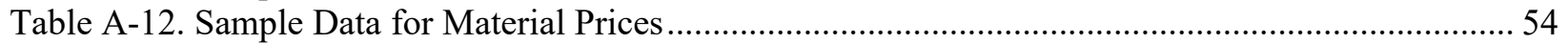

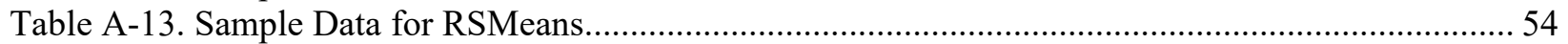

Table A-14. Site Facility Building Area Defaults as Function of Project Size .........................................55

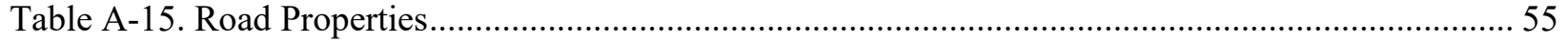

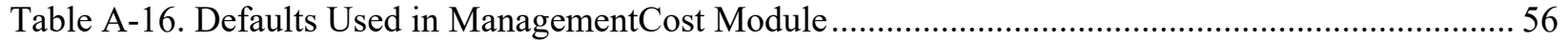

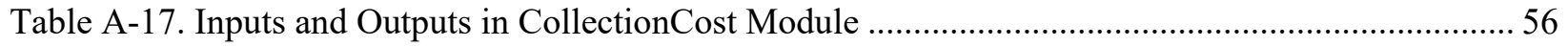

Table A-18. Inputs and Outputs in FoundationCost Module ..................................................................5

Table A-19. Inputs and Outputs in SitePreparationCost Module ........................................................... 59

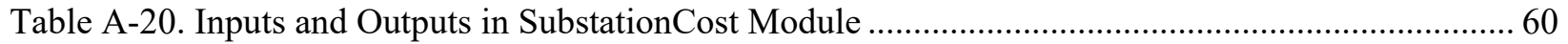

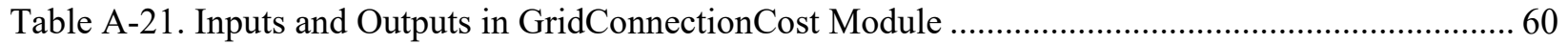

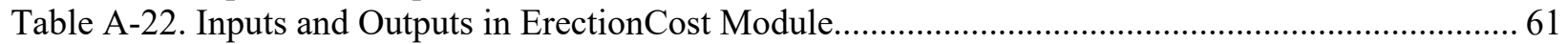

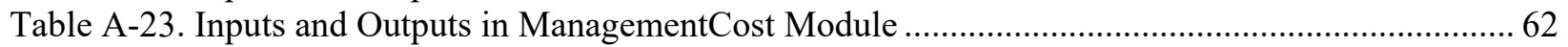

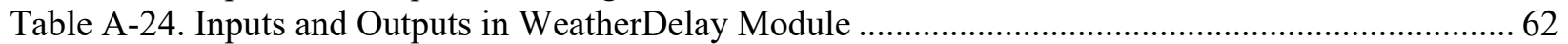




\section{Introduction}

Wind power comprised $6.6 \%$ of total net generation in the United States in 2018, and it is projected to become the largest source of renewable electricity generation in 2019 (1). However, significant cost and performance improvements in wind power technology will be needed in order to achieve the U.S. Department of Energy's Wind Vision report scenarios of wind power supplying $20 \%$ of national end-use electricity demand by 2030 and $35 \%$ by 2050 (2). Although the contiguous United States has the technical resource potential to generate up to 32,700 terawatt-hours of electricity per year (more than eight times the amount of electricity that was consumed in the United States in 2018) from land-based wind plants (2), the development of much of this resource is not currently economically feasible because of technology constraints, site complexities, competition from lower cost power sources, or other factors.

Improving the cost and performance of wind power plants will likely involve modifying multiple aspects of wind plant design and operation, including improving methods for turbine erection and modifying the plant layout to increase energy capture, altering maintenance procedures to reduce operational costs, and changing aspects of the balance of system (BOS) to decrease construction costs. BOS costs include all of the costs associated with installing a wind plant, such as permitting, labor, material, and equipment costs associated with site preparation, foundation construction, electrical infrastructure, and tower installation. BOS costs do not include the capital costs of the turbine or operation and maintenance (O\&M) costs associated for the plant. However, depending on site-specific factors, the BOS costs for land-based wind plants comprise about one-third of the project's total investment costs (3). As turbine technology and costs change, modeling how BOS costs change with different foundation designs, tower technologies, and turbine installation methods is valuable for understanding the potential for cost reductions in a wind project's total investment costs.

\subsection{Purpose of the Model}

The goal of NREL's Land-based BOS Systems Engineering (LandBOSSE) model is to provide researchers, analysts, wind power developers, government agencies, and the public with a flexible tool that can be used to estimate the BOS costs associated with land-based wind plants. The model is also intended to provide a common framework for modeling costs, and it is designed in a modular manner to allow future modifications and user-created enhancements. For example, although the model was originally developed for estimating the BOS costs for utilityscale wind plants, the model framework is adaptable and could accommodate smaller facilities with modifications.

The model aims to achieve an American Association of Cost Engineers Class 4 rating with an expected accuracy range of $-10 \%$ to $-20 \%$ on the low end of estimation (underestimation) and $+20 \%$ to $+50 \%$ on the high end (overestimation) (4). As a result, the model is not intended to be used for project planning or budgeting; it is instead designed to provide a moderate level of information for screening different design concepts and studying their feasibility. For example, the model could be used to generate rough order-of-magnitude estimates of BOS costs for different types of turbines, foundation materials, labor rates, and crane sizes. 


\subsection{Approach to Model Development}

LandBOSSE was developed using a four-tiered approach, which required collecting proprietary data and input from multiple sources, integrating these data with publicly available sources, and curating these sources for use within the model. First, we identified the major categories of BOS costs for land-based wind plants and mapped their underlying processes to input and output variables (see Section 2). Then, we reviewed our mapped process diagrams with industry experts and collected data for the calculations. Third, in parallel with industry review, we implemented the process diagrams based on our knowledge of the construction of conventional steel tower turbines; this step required simplifying our implementation of the detailed process diagrams in Section 2 because of data or other limitations (see Section 3). Finally, we verified that the model outputs aligned with industry data. In some cases, because of data limitations or other constraints, we use curve fits of industry data rather than implementing detailed process-based approaches (e.g., development, management, substation, and grid connection modules). Finally, we talked with industry experts to evaluate trends in technology innovation and updated or expanded the model structure to accommodate potential innovation pathways. Overall, the model is based on a bottom-up assessment of inputs and outputs associated with each BOS operation and, where needed, it is supplemented by top-down estimates of costs from industry.

This type of cost estimation tool may be of value to industry, as it may increase the fidelity of cost estimation in some cases. Industry currently performs high-level, low-fidelity cost analysis using empirical data to evaluate whether projects are worth pursuing and executes low-level, high-fidelity cost studies to more accurately assess costs for project bidding. However, the lowfidelity cost estimates used in industry cannot be used to examine how changes in technology development might impact these estimates and the high-fidelity site-specific analysis, which is often executed separately by experts in each BOS cost category (e.g., site preparation, collection, and erection), is time-consuming. LandBOSSE allows for costs to be evaluated at a mid-level between the two levels used in industry, which allows for relatively fast iteration around technology alternatives and holistic analysis of changes in BOS costs across cost categories.

This report describes the approach, methods, and equations used to develop LandBOSSE Version 2.1 (LandBOSSE 2.1). Future versions of the model may incorporate additional processbased capabilities or modify calculations within the code. Refer to the GitHub repository at https://github.com/WISDEM/LandBOSSE for the current version of the documentation and code.

\section{Land-Based BOS Process Descriptions}

Land-based BOS construction costs can be broken down into eight categories: 1) development, 2) management, 3) site preparation, including road construction, 4) foundation construction, 5) turbine erection, 6) collection system construction, 7) grid connection costs, including transmission and interconnection, and 8) substation construction. The detailed processes associated with each of these modules is outlined in the sections that follow. Note that the process diagrams presented are intended to serve as an idealized model of actual BOS processes and are not implemented completely within LandBOSSE 2.1 (see Section 3 and 4 for details about the implementation within the model). The descriptions and figures provided in this section are intended to illustrate the most important inputs, calculated parameters, process steps, 
and final costs within each BOS cost category. The actual implementation of these processes within LandBOSSE 2.1 is described in Section 4.

\subsection{Site Development}

Developing a site for a land-based wind plant includes evaluating the quality of the wind resource, obtaining environmental permits, marketing the power, acquiring the necessary land, and assessing distribution costs. Various factors influence the costs of each of these steps, which are primarily driven by the terrain complexity, the number of turbines, the turbine rating, and the regional location of the site (see Figure 1). The total development costs equal the sum of the costs for all underlying processes.

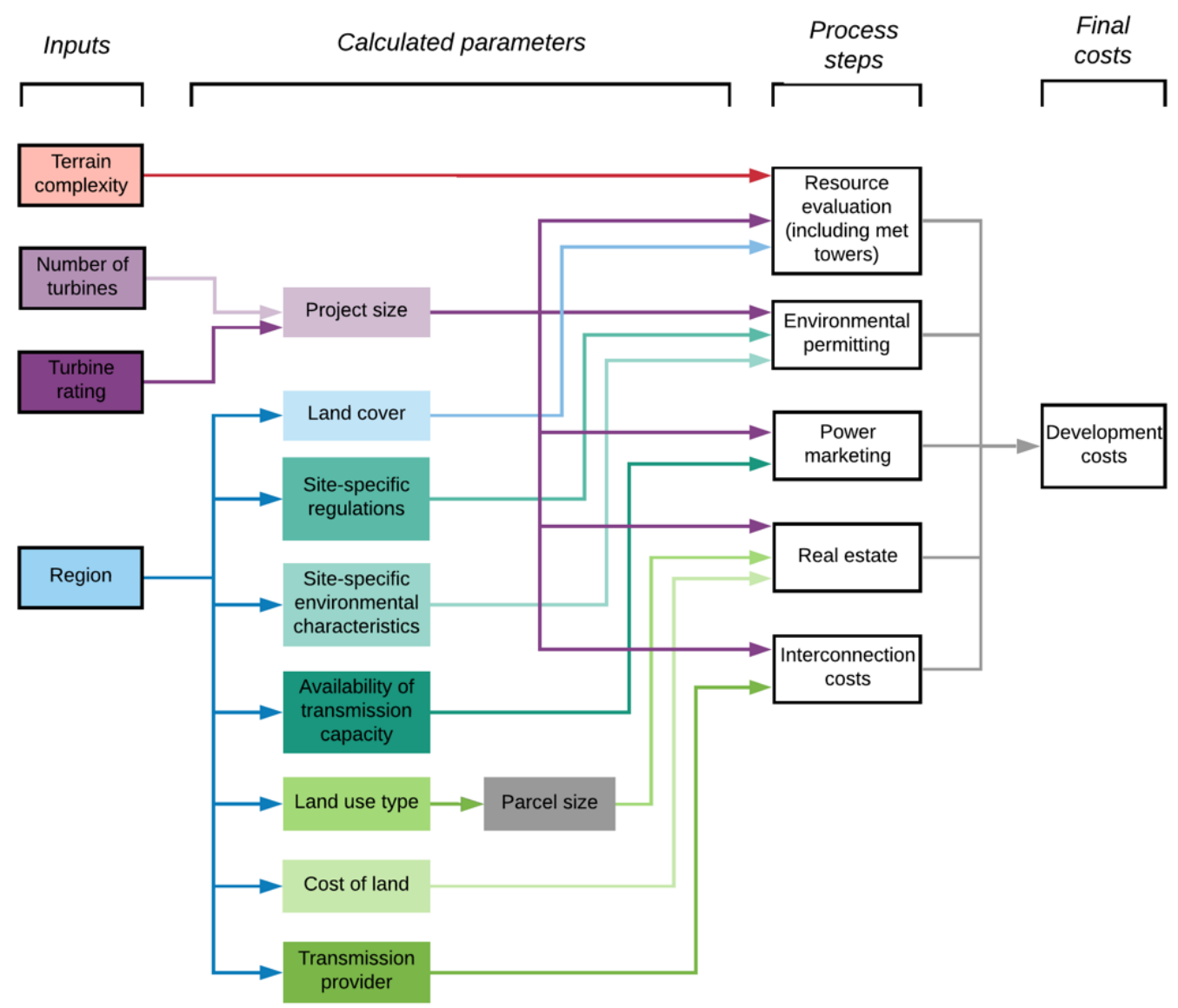

Figure 1. Process diagram for site development 


\subsection{Management}

Management at a land-based wind plant includes acquiring insurance, permitting construction, bonding the project, managing the project, mark-up and contingency costs, performing sitespecific engineering, and developing the facilities for site access and staging. Various factors impact the costs for each of these steps, but they are primarily driven by the project value, builder size, number of turbines, turbine rating, and regional location of the project (see Figure 2). The total management costs equal the sum all costs for the underlying processes.

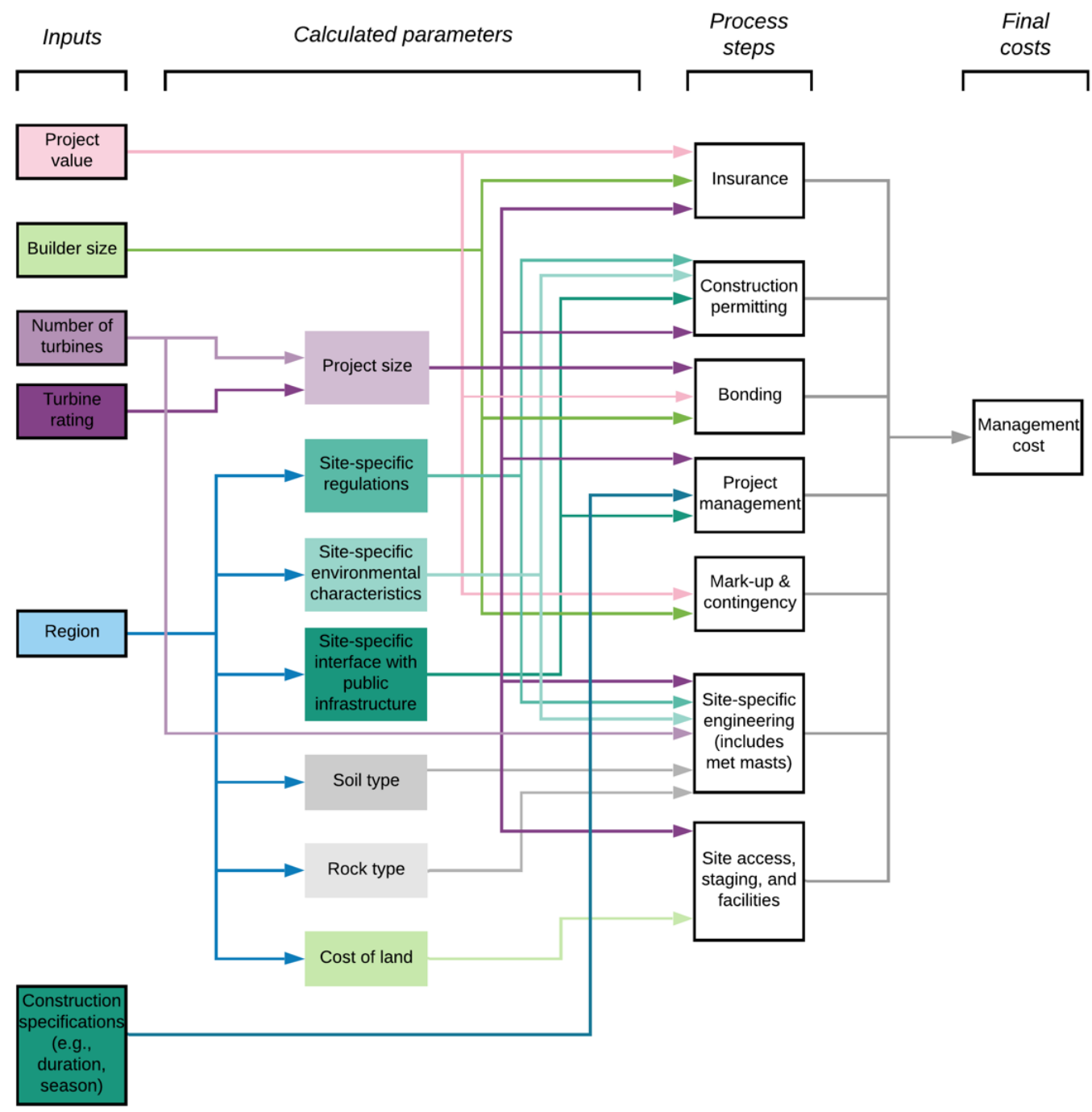

Figure 2. Process diagram for management 


\subsection{Site Preparation}

Preparing the site for a land-based wind plant is a detailed process that includes constructing roads and ranges from performing a road survey and clearing the roads to compacting the soil and placing rock. Various factors influence each of the steps in the process, and they are primarily driven by the site and terrain complexity, regional location of the project, bearing pressure of the trailers, method of crane travel, distance to a quarry, crane width, existing road crossings, site transport method, specifications for the road design, blade length, turbine spacing, number of turbines, and turbine rating (see Figure 3). We separated the parameters that influence the costs of each underlying site preparation process into four major categories: engineering hours, person hours, equipment hours, and quantity of materials. The final site preparation costs are then computed for labor, fuel, equipment, and materials based on the prices associated with each of these goods.

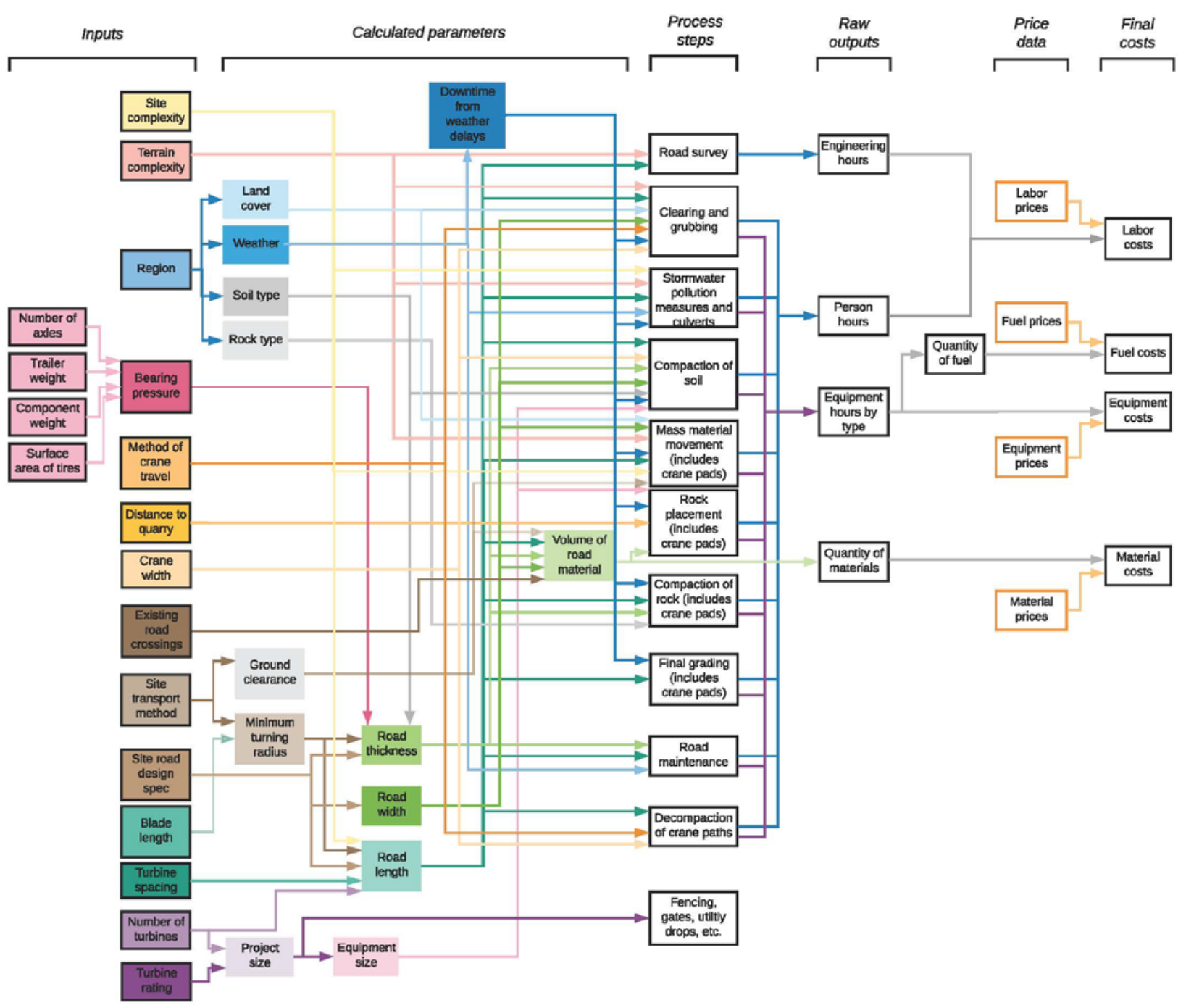

Figure 3. Process diagram for site preparation 


\subsection{Foundation Construction}

Constructing tower foundations for a land-based wind plant is largely driven by the foundation design, and it includes excavating the site, putting down rebar and constructing a bolt cage, pouring concrete for the base, constructing the pedestal, and backfilling the foundation. Various factors influence each of these processes, but they are primarily driven by the number of turbines, the duration of construction, the regional location of the project, the rotor diameter, the hub height, the turbine rating, whether a buoyant foundation design is required, the seismic zone of the site, and the type of tower technology being used (see Figure 4). The dominant parameters that influence the foundation design, and therefore the foundation construction costs, are the soil type and the foundation loads.

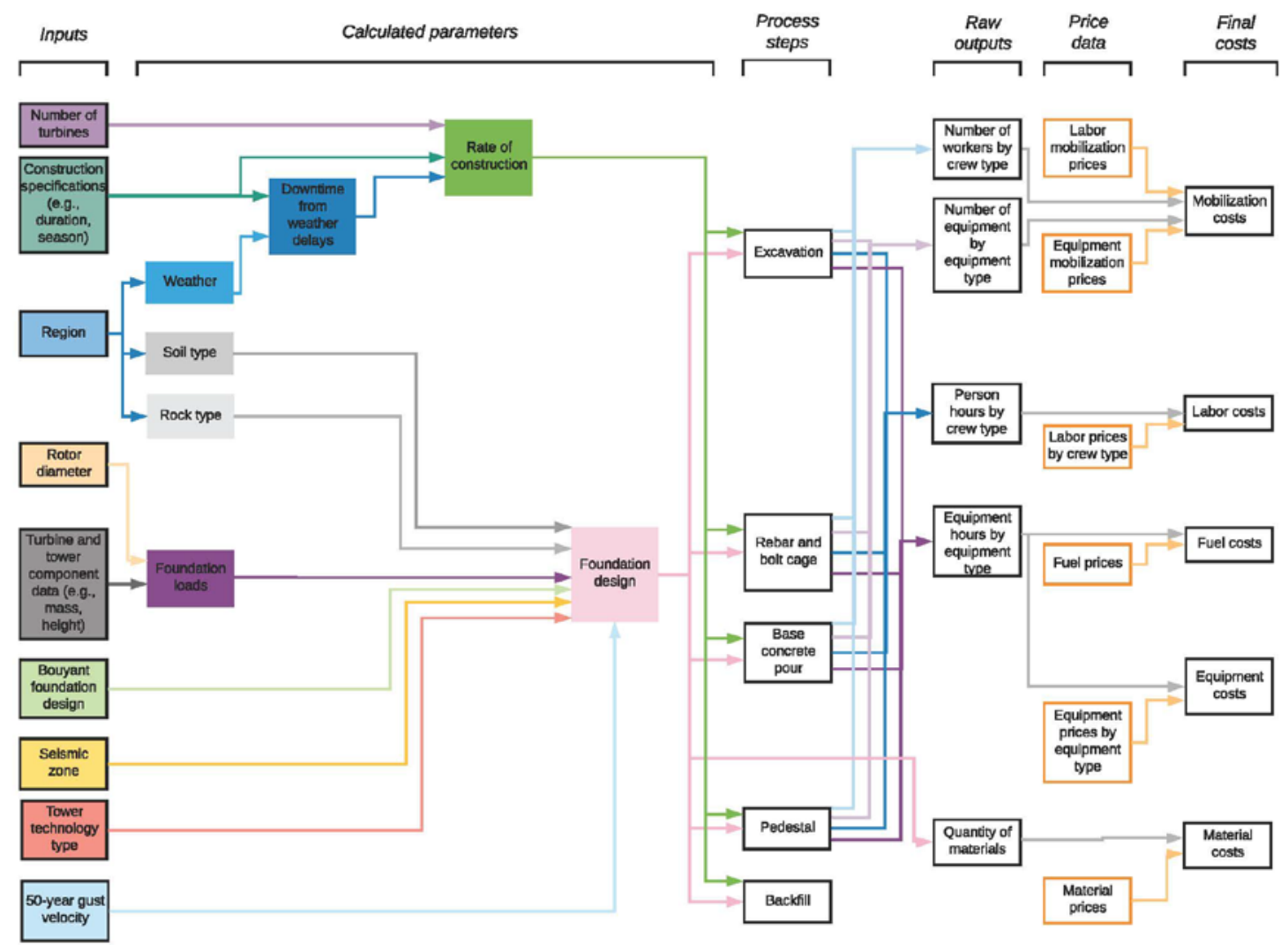

Figure 4. Process diagram for foundation construction 


\subsection{Turbine Erection}

As shown in Figure 5, the traditional process of erecting a turbine starts with the delivery of parts, including the rotors, the nacelle, and the tower sections. The tower is then installed with a crane, which is often split into two phases so different cranes can be used for the base and top of the tower. The rotors and nacelle are installed using the same crane used for the top of the tower, and any civil work related to crane travel is performed alongside the other processes. The major drivers of the erection costs are the size, quantity, and type of cranes and the crews required for the project, which is influenced by the risk of short-term weather (specifically wind) delays and the size and weight of the tower and turbine components. The number of crane breakdowns required when moving the crane from turbine to turbine is also an important driver of erection costs.

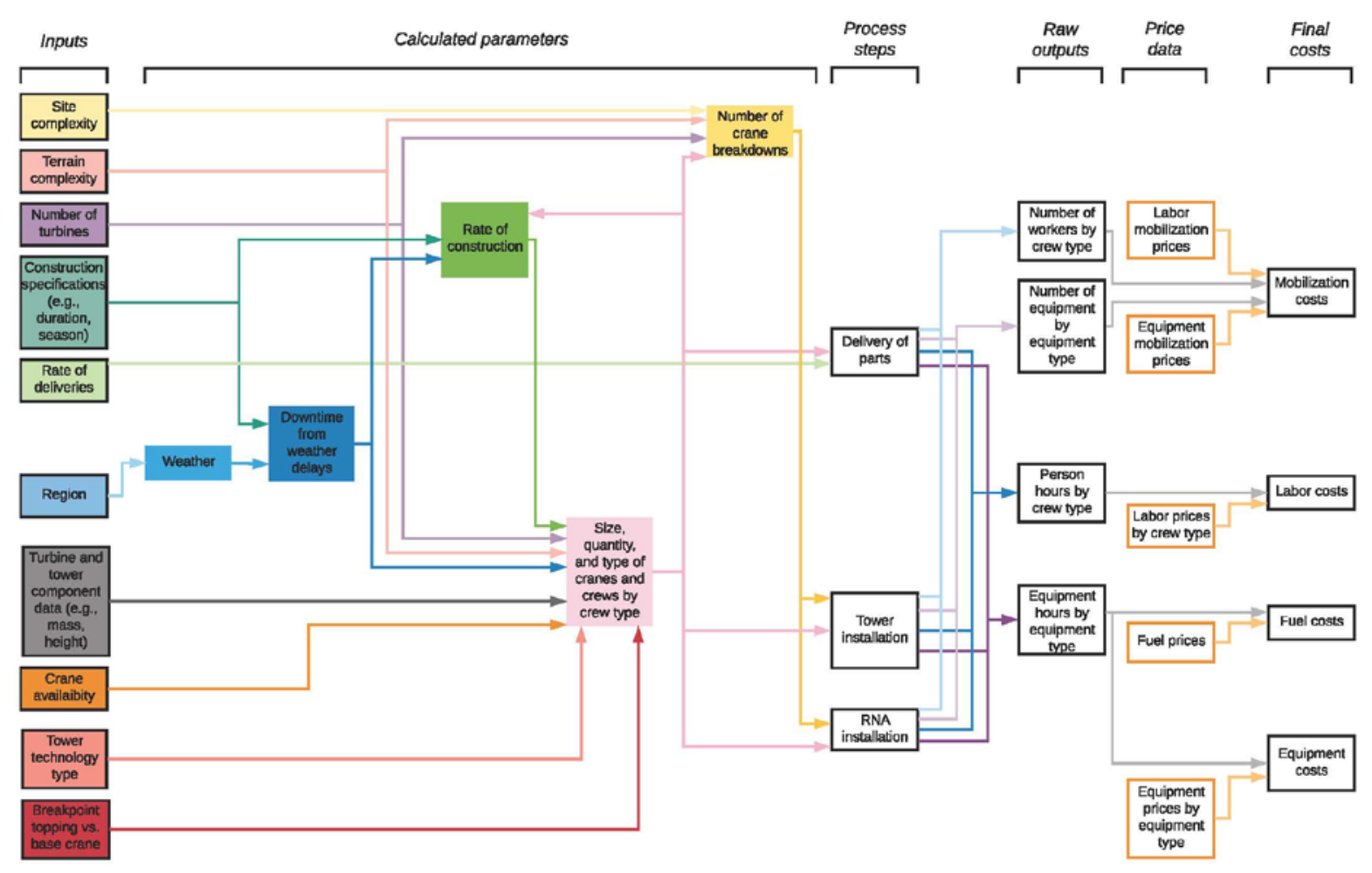

Figure 5. Process diagram for the erection of the tower and rotor nacelle assembly 


\subsection{Collection System Construction}

Installing a collection system for a land-based wind plant involves preparing the site for the type of collection system being used (e.g., trenching, boring, or overhead preparation) and then installing the conductors. The primary factors that influence the cost of the collection system are the number of electrical connections - which is a function of numerous input parameters - along with the type of collection system and the volume of cable required for the project. The major input parameters for collection system costs are therefore the site complexity, terrain complexity, electrical system losses, number of turbines, turbine rating, turbine model, average distance to the substation, regional location of the project, and plant layout (see Figure 6).

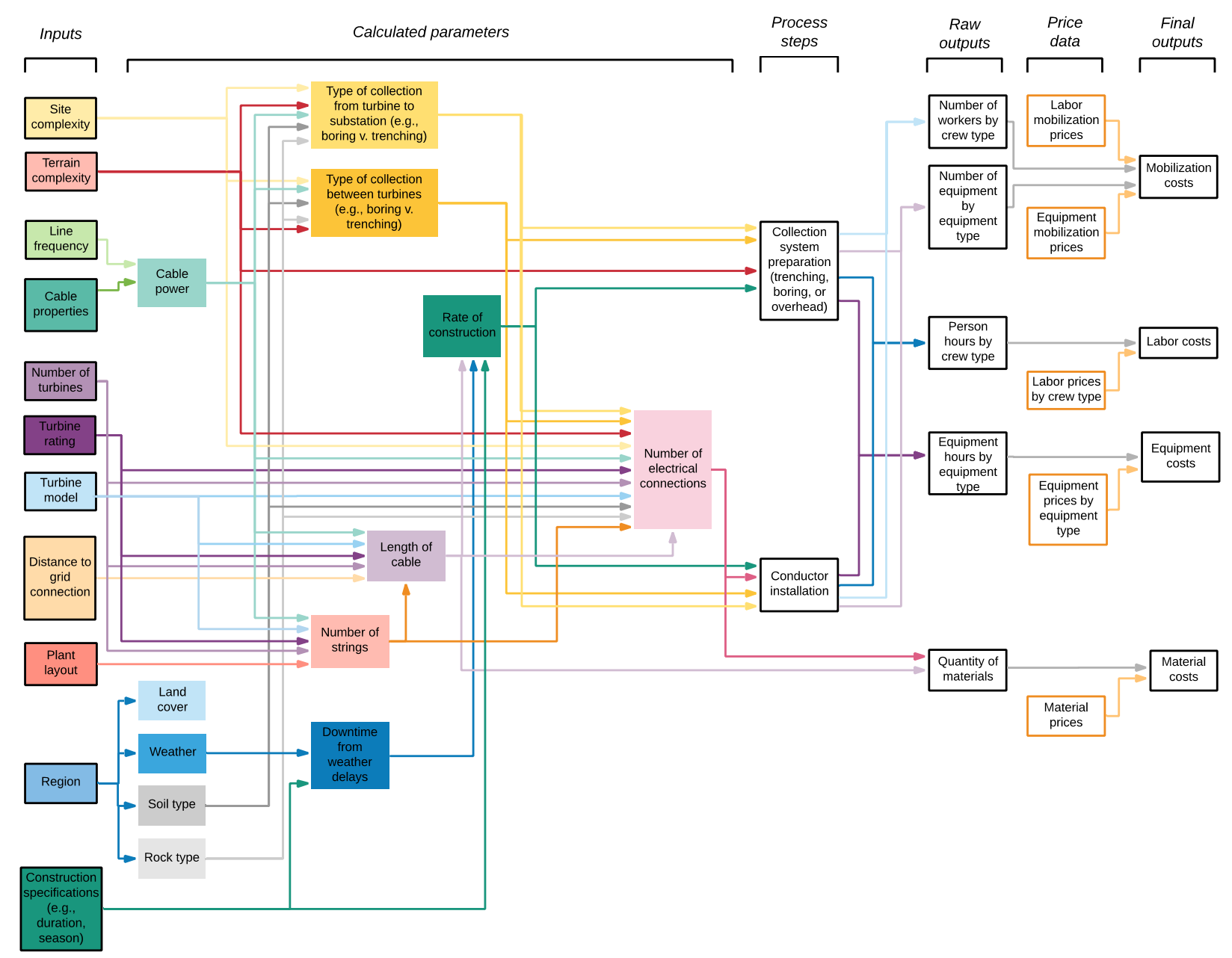

Figure 6. Process diagram for the collection system 


\subsection{Grid Connection}

The grid connection process, which includes transmission and interconnection, for utility-scale, land-based wind plants includes performing a land survey, clearing and grubbing the area, implementing storm-water pollution measures, installing the poles, installing the conductor, and restoring the right of way. The costs of these processes are driven by the terrain complexity, the line voltage, the line length, and the regional location of the project (see Figure 7).

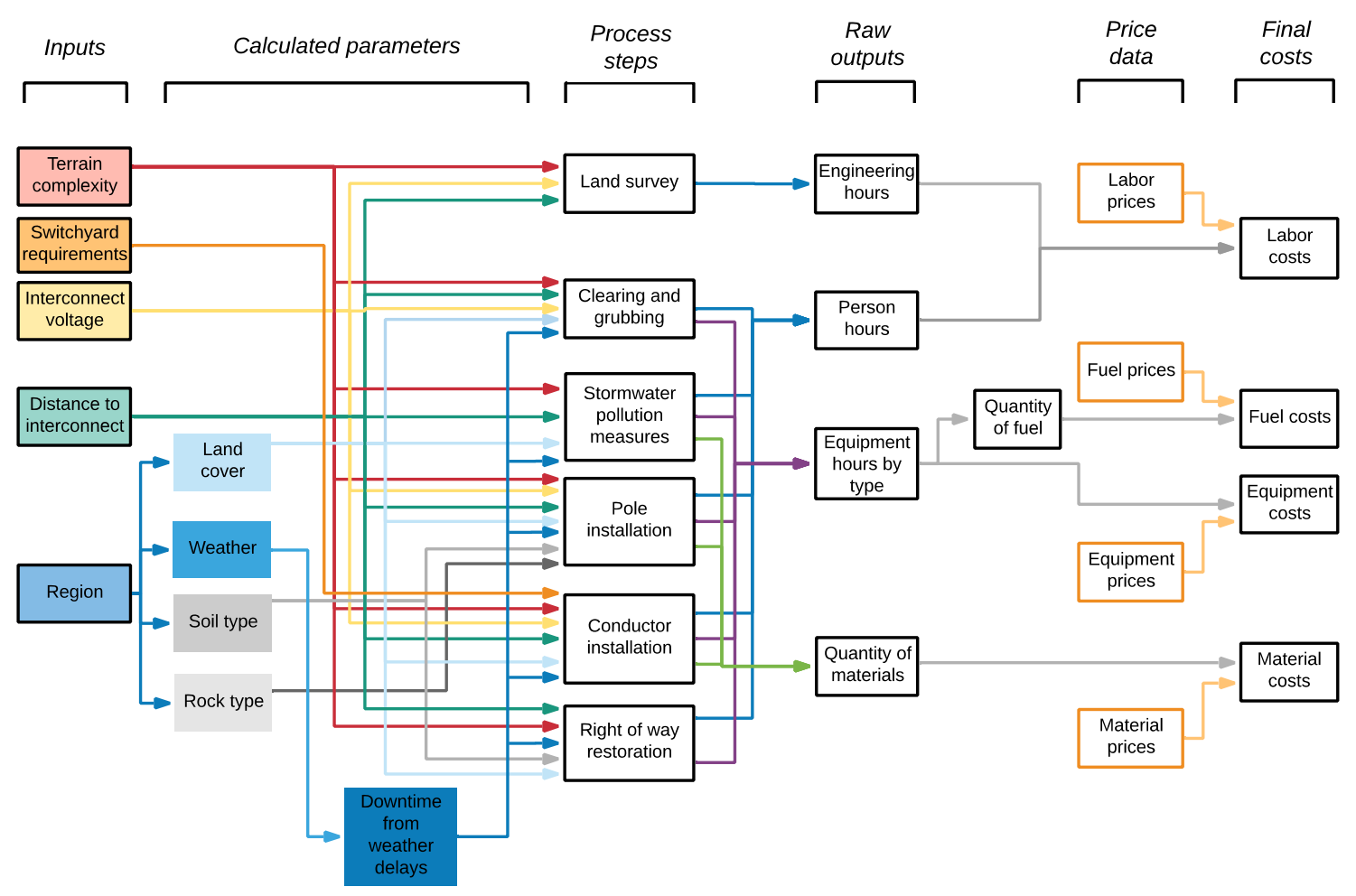

Figure 7. Process diagram for grid connection 


\subsection{Substation Construction}

Substation construction for land-based wind plants includes performing a land survey, clearing and grubbing the area, excavating, installing foundations, implementing storm-water pollution measures, installing the dead-end structures, installing the conductors, transformers, relays, meters, switches, controls, and breakers as well as restoring the disturbed areas after construction is complete. The costs of these processes are driven by the plant size, terrain complexity, rock and soil conditions on site, interconnection and collection voltages, the collection system design, and the regional location of the project (see Figure 8).

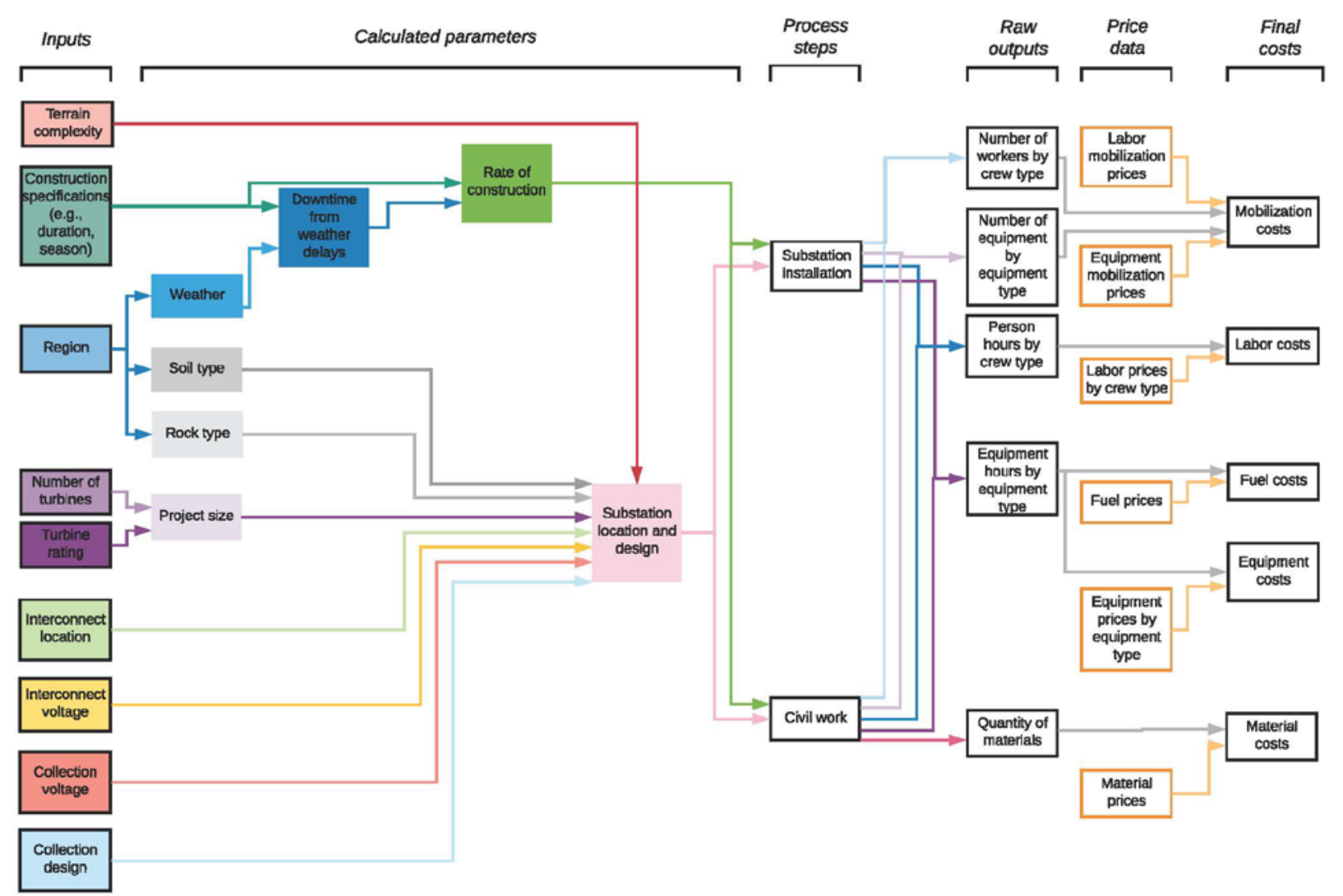

Figure 8. Process diagram for substation construction 


\section{LandBOSSE Architecture}

As described in Section 1, this report describes the approach, methods, and equations used to develop LandBOSSE 2.1. The model uses a modular software architecture developed in Python 3.7 and includes nine BOS cost calculation modules (see Figure 9). ${ }^{1}$

At its highest level, the software's interface is a set of input and output Python dictionaries. A user only needs to instantiate the Manager class (i.e., highest-level class; see Figure 9) with an input Python dictionary that contains the required set of inputs and an empty Python dictionary to store the outputs. The Manager class owns and coordinates the sharing of input and output data with all lower-level modules. This design is intended to prevent interdependencies between the any of the modules and to provide a standard, single point of entry into the LandBOSSE library. This structure will allow for additions of new input and output data without a risk of breaking the software because of hidden dependencies. Additionally, new modules can be incorporated by simply attaching them directly to the Manager class.

The LandBOSSE software includes a mix of two architectural styles: the pipe and filter style, and the data abstraction and object-oriented organization style. The input and output dictionaries are analogous to pipes, and each of the modules are similar to filters that transform input data streams; the modules themselves (including the Manager class) represent a standalone class with their own unique share of the data and relevant operations.

When combined, the two styles of architecture described above achieve a few important design benefits: (1) preserving the integrity of the software, (2) limiting lower-level interdependencies (of data and operations that process these data) between the modules, and (3) allowing reuse of the software, as it can be easily connected to other tools. For example, as long as the necessary input data are provided, each module can be run independently of the rest of the code. All modules can also be run together to execute total BOS costs for all cost categories.

\footnotetext{
${ }^{1}$ Future versions of LandBOSSE may differ from the design and implementation described here; refer to the GitHub repository at https://github.com/WISDEM/LandBOSSE for the latest version of the software documentation and code.
} 


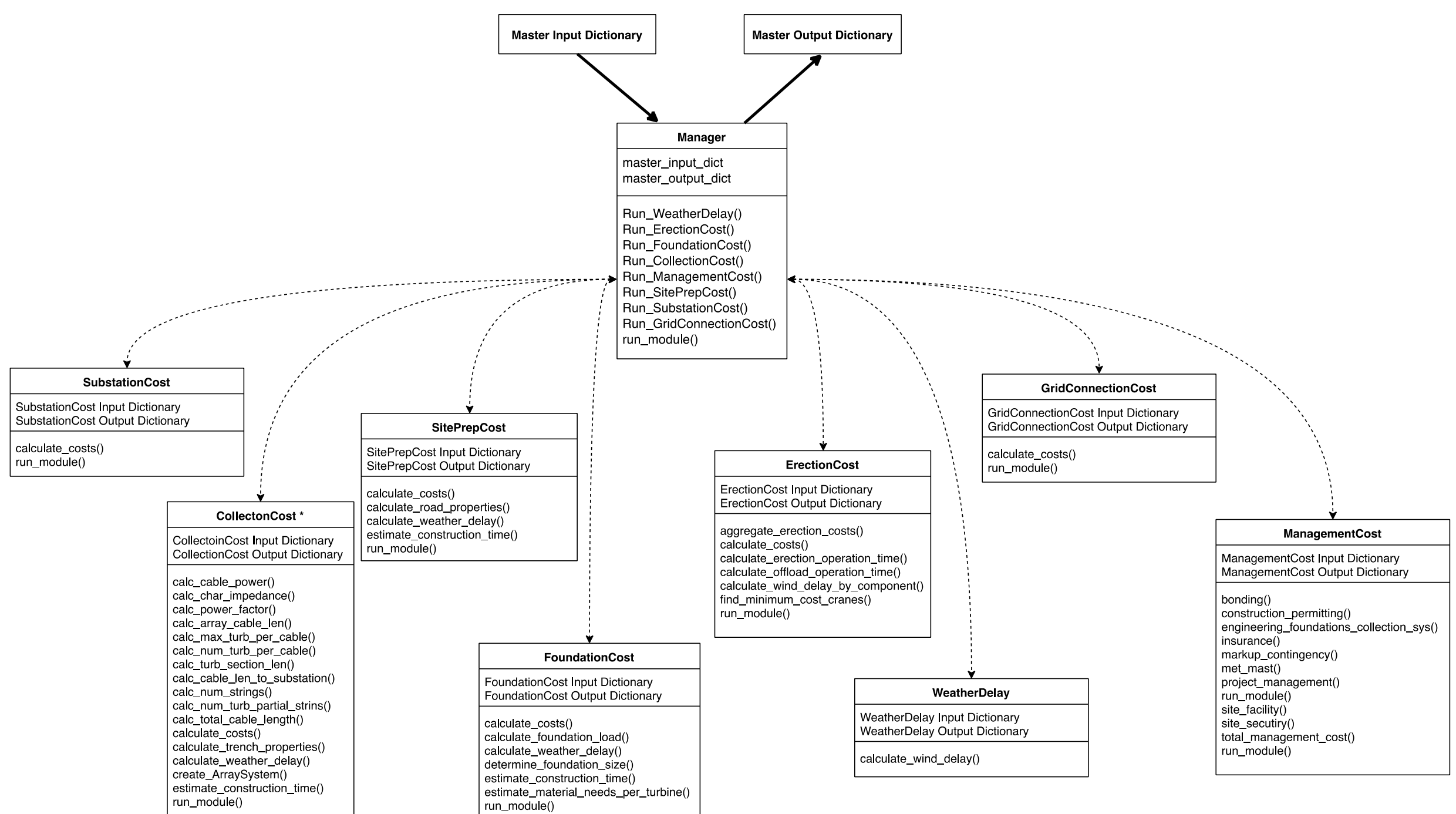

\section{Figure 9. LandBOSSE 2.1 Architecture}

${ }^{*}$ CollectionCost module in LandBOSSE is made up of three classes. However, it is represented as a single class here for the sake of simplicity. Detailed inputs and outputs for each module can be found in the appendix. 


\section{LandBOSSE Modules}

As described in Section 3, the LandBOSSE model was developed in a modular manner to allow it to be updated and modified fairly easily and to accommodate a variety of factors, including tower technologies, turbine types, and site-specific parameters. This section describes the approach, methods, and equations used to develop LandBOSSE 2.1. ${ }^{2}$

As shown in Figure 9, LandBOSSE 2.1 consists of nine modules that correspond to each of the eight land-based BOS construction phases and an additional weather delay module. As shown in Table 1, LandBOSSE 2.1 is implemented using a hybrid of process-based equations and curve fits of empirical data. Five of the modules are implemented using the process-based approach, which involves computing equipment hours, labor hours, mobilization costs, and material needs, and combining them with price data for each of these parameters. Because of data limitations or other constraints, the other four modules are currently implemented using curve fits of industry data. Total costs are summed within each module and over all modules, and, where possible, costs are broken down by type, including mobilization, labor, fuel, equipment, and materials. All costs are computed and reported in U.S. dollars (USD). The following sections, which are organized by implementation style (process-based versus empirical), detail the implementation of each module.

Table 1. Implementation Method Used for Each Module in LandBOSSE 2.1

\begin{tabular}{ll}
\hline Implementation Method & Module Name \\
\hline Process-based equations & SitePreparationCost \\
& FoundationCost \\
& ErectionCost \\
& CollectionCost \\
& WeatherDelay \\
Curve fit of empirical data & DevelopmentCost ${ }^{\mathrm{a}}$ \\
& ManagementCost \\
& GridConnectionCost \\
& SubstationCost \\
\hline
\end{tabular}

${ }^{a}$ DevelopmentCost is currently implemented as a user input.

\subsection{Process-Based Modules}

The process diagrams in Section 2 illustrate the general approach used to implement each of the process-based modules. Within these modules, BOS costs are calculated based on user-specified labor, fuel, equipment, material, and mobilization prices in combination with process-based calculations that compute parameters such as the number of workers, number of equipment, equipment hours, person hours, and quantity of materials. However, because of data limitations or other constraints, the implementation of the process-based modules differs from the ideal

\footnotetext{
${ }^{2}$ Future versions of LandBOSSE may differ from the design and implementation described here; refer to the GitHub
} repository at https://github.com/WISDEM/LandBOSSE for the latest version of the software documentation and code. 
process diagrams illustrated in Section 2. The content and figures in this section describe the current implementation of these processes within LandBOSSE 2.1.

\subsubsection{SitePreparationCost}

We implement the site preparation cost module using the highlighted structure in Figure 10. Because of data restrictions or other constraints, we are unable to implement all the ideal inputs and calculated parameters. However, we attempt to either (1) use proxy inputs when the needed data are unavailable (e.g., operation time is used as a proxy for project size) or (2) implement a calculated parameter as a user input (e.g., weather) rather than derive the data directly from the higher-level input (e.g., region).

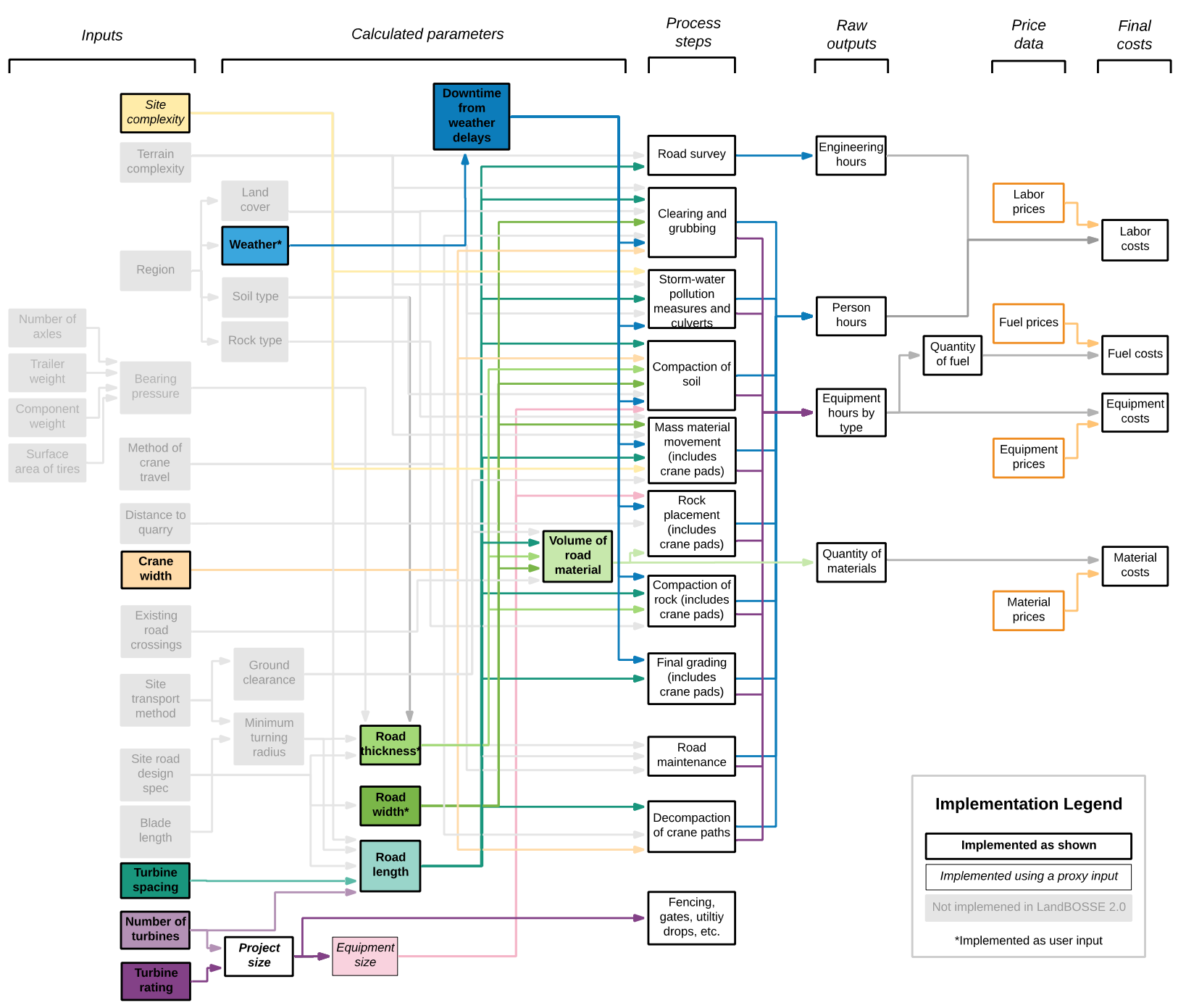

Figure 10. Implementation of SitePreparationCost module in LandBOSSE 2.1

Proxy inputs are listed in the appendix. 
As shown in Figure 10, the general structure of the site preparation (SitePreparationCost) module includes:

1. Estimating the road length based on the number of turbines and the average turbine spacing

2. Determining the time required for five major operations associated with new site preparation based on road length, road width, road thickness, and crane width, including:
A. Topsoil stripping and stock piling, where organic material and topsoil must be removed and stockpiled for site preparation and for remediation of the crane paths
B. Compacting of subgrade and shoulders for crane paths
C. Placing of aggregate
D. Rough grading of aggregate
E. Compacting of aggregate.

3. Determining the additional time needed for weather delays for new site preparation

4. Estimating the labor, material, and equipment costs based on the road length, road width, road thickness, operational time, and additional time for weather delays for new site preparation

5. Estimating the relative contribution of existing roads compared to new roads and calculating the total site preparation cost.

For the purposes of this model, road refers to the surface on which wheeled traffic such as turbine component delivery trucks travel. The road is typically made of compacted crushed stone and is typically $3.7-4.9 \mathrm{~m}$ wide and $0.2 \mathrm{~m}$ thick (model defaults for road width and thickness are $4.9 \mathrm{~m}$ and $0.2 \mathrm{~m}$ respectively). Each of the road cost calculations is detailed below.

In Step 1, the total length of road, $L_{r}$ (in $\mathrm{m}$ ), for the project is calculated by estimating an average road length based on a simple, semi-rectangular turbine layout constructed on flat to rolling terrain and is given by:

$$
L_{r}=\left(N_{t}-1\right) * D_{r} * S_{t}+l_{\text {adder }}
$$

where $N_{t}$ is the number of turbines, $D_{r}$ is the diameter of the rotor in meters, $S_{t}$ is the spacing of the turbines relative to the rotor diameter (unitless), and $l_{\text {adder }}$ is the excess roads for access to road strings from existing public roads and/or highway.

In Step 2, the operational time is calculated for five major site preparation operations. RSMeans Construction Cost Database (RSMeans) or industry data for labor and equipment operation rates are combined with the road length to determine the operation time for these five major operations associated with site preparation. The detailed calculations for each operation are outlined below.

In Step 2a, we calculate the operational time for stripping and stock piling topsoil, which is required to reach a suitable subgrade that will have a suitable bearing capacity depending on road thickness. Stripping and stock piling is performed for the width of the road and the area for crane 
paths - large shoulders of the road used for crane travel. For the purposes of this model, we assume the crane path width is equal to the width of the crane that is specified by the user (typically 9-11 meters) plus 1.5 meters to allow shoulders for crane travel. The depth of organic material and topsoil can vary widely depending on ground cover and geographic region, but the model does not currently take these factors into account. The operational time for stripping and stock piling topsoil, $O T_{s t}$ (in days), is given by:

$$
O T_{s t}=\frac{\left(L_{r} *\left(W_{c}+1.5\right) * d_{s u b}\right)}{T_{s t}} * \frac{1.30795 \text { cubic yards }}{1 \text { cubic meter }} \frac{\left(L_{r} *\left(W_{c}+1.5\right) * d_{s u b}\right)}{T_{s t}} * \frac{1.30795 \text { cubic yards }}{1 \text { cubic meter }}
$$

where $L_{r}$ is the length of the road (in $\mathrm{m}$ ) given by Eq. $1, W_{c}$ is the width of the crane used for erection (in $\mathrm{m}$; default value is $11 \mathrm{~m}$ ), $d_{s u b}$ is the depth of the subgrade (default value is $0.1 \mathrm{~m}$ ), and $T_{s t}$ is the daily output for stripping and stock piling topsoil (in cubic yards per day).

It is important to note that cranes typically have low bearing pressures because of the large surface area of the tracks and thus do not require a constructed road to travel across. However, it is common practice to construct dedicated crane paths to minimize crane travel time and breakdowns as well as relieve traffic congestion. The cost of developing dedicated crane paths is a function of project layout, local topography, and site complexity. This model assumes all crane travel either occurs on road shoulders or does not require the construction of dedicated crane paths. Thus, the model does not include costs associated with developing dedicated crane paths.

In Step 2b, we estimate the time, in days, required to compact the subgrade and shoulders for crane paths, $O T_{S C}$, using an equation similar to Eq. 2, which is given by:

$$
O T_{s c}=\frac{\left(L_{r} *\left(W_{c}+1.5\right) * d_{s u b}\right)}{T_{s c}} * \frac{1.30795 \text { cubic yards }}{1 \text { cubic meter }}
$$

where $T_{s c}$ is the daily output for compacting the subgrade and shoulders (in cubic yards per day).

In Step 2c, we calculate the operational time, in days, required to place aggregate, $O T_{p}$, which is given by:

$$
O T_{p}=\frac{\left(L_{r} * W_{r} * t_{r}\right)}{T_{p}} * \frac{1.30795 \text { cubic yards }}{1 \text { cubic meter }}
$$

where $t_{r}$ is the thickness of the road (in $\mathrm{m}$; default value is $0.2 \mathrm{~m}$ ), and $T_{p}$ is the daily output for placing aggregate (in embankment cubic yards per day). Note that the $\left(L_{r} * W_{r} * t_{r}\right)$ term is the compacted volume of the road, which is generally measured in units of embankment cubic yards (ECY).

In Step $2 \mathrm{~d}$, the operational time, in days, for rough grading aggregate, $O T_{g}$, is given by:

$$
O T_{g}=* \text { ceiling }\left(\frac{t_{r}}{l_{h}}\right) * \frac{1.30795 \text { cubic yards }}{1 \text { cubic meter }}
$$

where $L_{r}$ is the length of the road (in $\mathrm{m}$ ) given by Eq. $1, W_{r}$ is the width of the road (in m; default value is $4.9 \mathrm{~m}$ ), $t_{r}$ is the thickness of the road (in $\mathrm{m}$; default value is $0.2 \mathrm{~m}$ ), $T_{g}$ is the daily output for grading aggregate (in embankment cubic yards per day), and $l_{h}$ is the lift height 
of each grading operation. Because the data we found for daily output for grading assume the material will be compacted at a lift height of $0.2 \mathrm{~m}$, if the road thickness is greater than $0.2 \mathrm{~m}$, multiple passes are necessary (as determined by the "ceiling" factor in Eq. 5).

In Step 2e, we evaluate the time, in days, needed to compact aggregate, $O T_{c}$ using an equation similar to Eq. 5, with:

$$
O T_{c}=* \text { ceiling }\left(\frac{t_{r}}{l_{h}}\right) * \frac{1.30795 \text { cubic yards }}{1 \text { cubic meter }}
$$

where $T_{c}$ is the daily output for compacting aggregate (in embankment cubic yards per day).

To calculate the potential for a wind delay in Step 3, we combine the operation times computed in Step 2 with a critical wind speed and height for wind delays (assumed to be $15 \mathrm{~m} / \mathrm{s}$ at $10 \mathrm{~m}$ for road construction) into the WeatherDelay module to estimate the potential wind delays that might occur for each crew during site preparation. Details can be found in Section 4.1.5.

In Step 4, we estimate the equipment and labor costs for each road operation based on operation times in Step 2, weather delays in Step 3, and RSMeans equipment and labor rates for each operation. We also calculate the total material cost for aggregate using the material price for aggregate and the volume of the road, $V_{r}$ (in loose cubic yards), which is given by:

$$
V_{r}=\left(L_{r} * W_{r} * t_{r}\right) * 1.39
$$

where $L_{r}$ is the length of the road (in m) given by Eq. 1, $W_{r}$ is the width of the road (in m; default value is $4.9 \mathrm{~m}$ ), $t_{r}$ is the thickness of the road (in $\mathrm{m}$; default value is $0.2 \mathrm{~m}$ ), and 1.39 is a factor from RSMeans that converts embankment cubic yards to loose cubic yards (LCY).

Steps 1 through 4 outline the approach for estimating the cost of developing new roads for the entire project. However, many wind farms use existing roads to transport turbine components rather than construct new roads. For example, the Blue Creek Wind Farm in Ohio (completed in 2012) used existing asphalt roads as well as smaller sections of cement-stabilized and new gravel roads (5). Because the one-mile grid of existing road infrastructure that is observed at Blue Creek is very common in agricultural areas and in the Western United States, we use the Blue Creek Wind Farm to inform the default model inputs associated with the relative contribution of existing and new site preparation (e.g., approximately $66 \%$ of the roads used for construction were existing asphalt roads and 33\% were new roads). In the case of Blue Creek, the developer paid for the preconstruction road improvements and the county waived the trucking permit costs.

To calculate the total road cost in Step 5, we consider the potential contribution from new versus existing roads. The total cost, $C_{\text {total }}$, is given by:

$$
C_{\text {total }}=\left(F_{\text {new }} C_{\text {new }}+\left(1-F_{\text {new }}\right) R_{q} C_{\text {existing }}\right)
$$

where $F_{\text {new }}$ is the fraction of new roads that will be built (default assumes $33 \%$ new); $C_{\text {new }}$ is the cost constructing new roads for the entire project, which is calculated by summing the values over all operations in Step 1 to $4 ; R_{q}$ is a nondimensional representation of road quality (default assumes 0.6 , which is representative of average road conditions); and $C_{\text {existing }}$ is the 
cost of installing existing roads for the entire project, which we assume in the default case to equal $0.5 C_{\text {new }}$.

\subsubsection{FoundationCost}

We implement the FoundationCost module of the LandBOSSE model using the highlighted structure in Figure 11. Because of data restrictions or other constraints, we are unable to implement all the ideal inputs and calculated parameters. However, we attempt to either use proxy inputs when the needed data are unavailable (e.g., bearing capacity is used as a proxy input for soil type) or implement a calculated parameter as a user input (e.g., weather) rather than derive the data directly from the higher-level input (e.g., region).

As shown in Figure 11, the general structure of the FoundationCost module includes:

1. Determining the critical loads for the foundation design based on turbine and tower components

2. Estimating the foundation size based on the critical loads

3. Calculating the quantity of material based on the foundation size

4. Determining the operational time for foundation construction based on foundation size

5. Determining the additional time for weather delays

6. Estimating the labor, material, equipment, and mobilization costs based on foundation size and additional time for weather delays

7. Calculating the total foundation cost.

Each of these calculations is detailed below. 


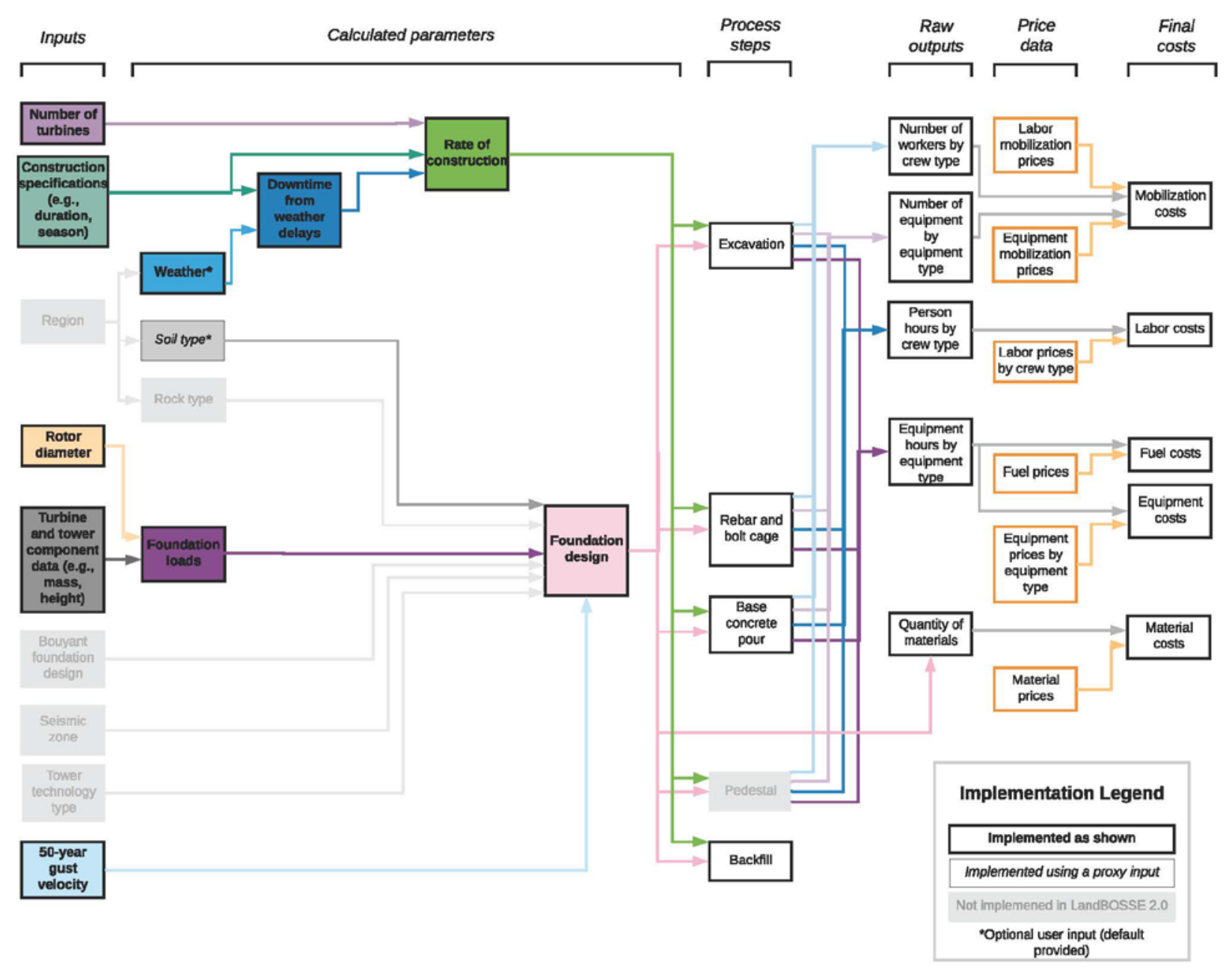

Figure 11. Implementation of FoundationCost module in LandBOSSE 2.1

Proxy inputs are listed in the appendix.

In Step 1, the FoundationCost module estimates the critical loads for the foundation design using the minimum design load guidelines outlined by the American Society of Civil Engineers (7). Note that the following equations are based on an idealized cylindrical gravity or spread-foot foundation (see Figure 12). Foundations such as rock anchors, monopiles, pile and cap, and other foundations may be more appropriate, depending on soil and rock types or labor and material costs, but the model does not currently calculate costs for these types of foundations. 
a) Side View
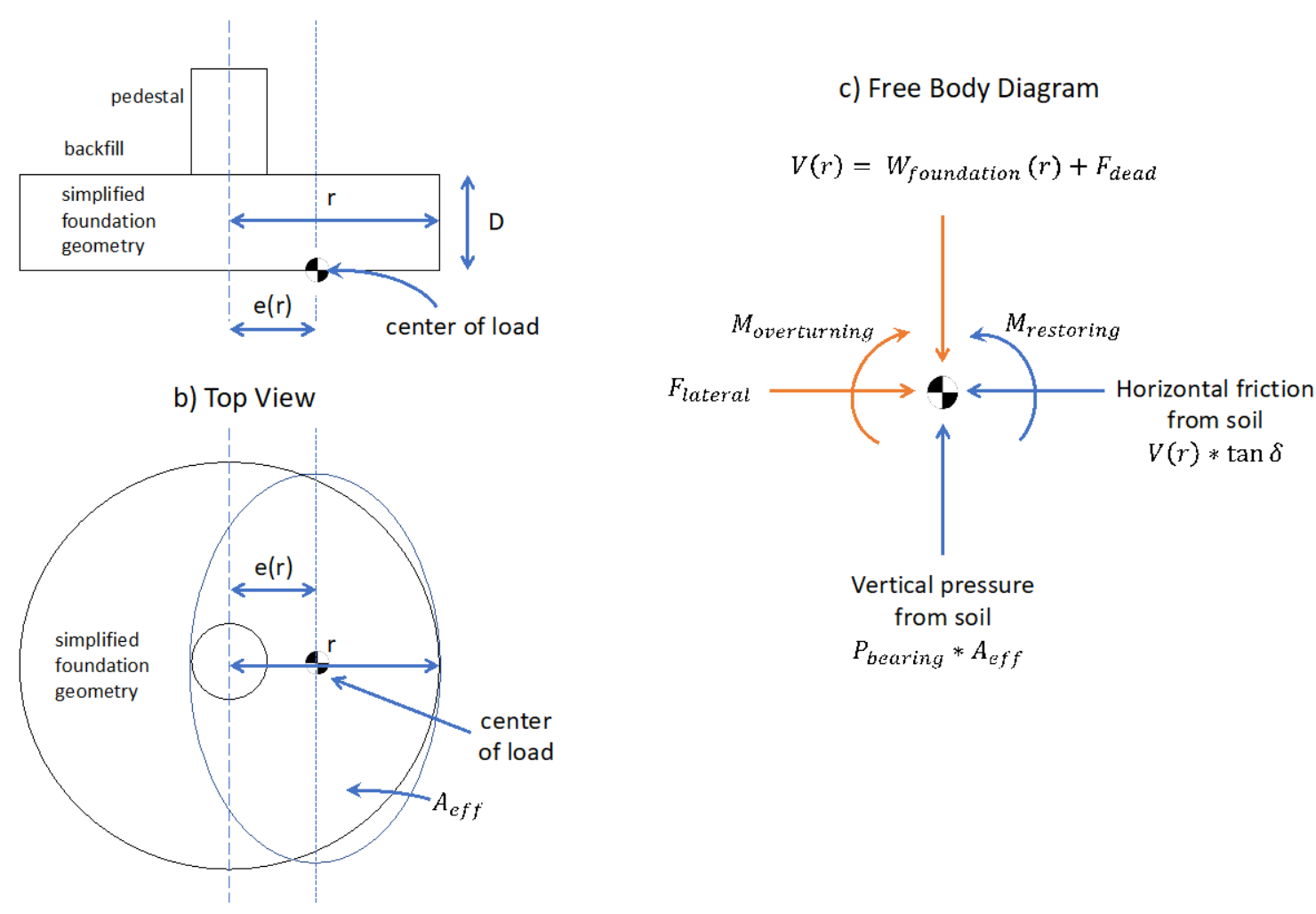

Figure 12. Illustration of idealized foundation design used in LandBOSSE

For the case of the idealized cylindrical spread-foot foundation shown in Figure 12, the total vertical force on the foundation, $V$ (in $\mathrm{N}$ ), which is a function of the foundation radius, $r$ (in $\mathrm{m}$ ), is given by:

$$
V(r)=W_{\text {foundation }}(r)+F_{\text {dead }}
$$

with the weight of the foundation, $W_{\text {foundation }}(r)$ (measured in $\mathrm{N}$ ) is a function of the foundation radius, and the dead weight of the turbine and tower, $F_{\text {dead }}($ in $\mathrm{N})$, given by:

$$
\begin{gathered}
W_{\text {foundation }}(r)=\left[\pi r^{2} * D\right] *\left[\frac{2}{3} U W_{\text {fill }}+\frac{1}{3} U W_{\text {concrete }}\right] \\
F_{\text {dead }}=\sum_{i=1}^{c} m_{i} * g
\end{gathered}
$$

where $D$ is the depth of the foundation (user input; default is assumed to be $3 \mathrm{~m}$ based on industry experience), $U W_{\text {fill }}$ and $U W_{\text {concrete }}$ are weight-per-volume of fill and concrete (default values are based on RSMeans data and are equal to 17.3 kilonewton per cubic meter $\left[\mathrm{kN} \mathrm{m}^{-3}\right]$ and $23.6 \mathrm{kN} \mathrm{m}^{-3}$ respectively), $m_{i}$ is the mass of the $\mathrm{i}^{\text {th }}$ component in metric tons, $c$ is the number of components in the tower and turbine, and $g$ is the acceleration due to gravity, which is equal to $9.81 \mathrm{~m} / \mathrm{s}$. 
Based on the minimum design load guidelines outlined by the American Society of Civil Engineers (7), the magnitude of the lateral load from the $\mathrm{i}^{\text {th }}$ component of the tower, $F_{t o w e r, i}$ (in $\mathrm{N})$, is given by:

$$
F_{\text {tower }, i}=p_{\text {wind }, i} * G * C_{f} * A_{f, i}
$$

where $G$ is a gust factor (assumed to equal 0.85), $C_{f}$ is the force coefficient (assumed to equal $0.4), A_{f, i}$ is the projected area of the $\mathrm{i}^{\text {th }}$ component of the tower that is normal to the wind, and $p_{\text {wind }, i}$ is the pressure due to wind on the $\mathrm{i}^{\text {th }}$ component, which is equal to

$$
p_{\text {wind }, i}=0.613 *\left[2.11 *\left(\frac{z_{i}}{z_{g}}\right)^{\frac{2}{a}}\right] * K_{z t} * K_{z d} * V^{2}
$$

where $z_{i}$ is the height of the center of mass of the $i^{\text {th }}$ component in meters, $z_{g}$ is a constant equal to $274.32 \mathrm{~m}, a$ is a constant equal to $9.5, K_{z t}$ is a topographic factor (assumed to equal to 1 ), $K_{z d}$ is a wind directionality factor (assumed to equal 0.95 ), $V$ is the velocity of an extreme 50 -year wind gust in m/s. Equations 12 and 13 are derived from the American Society of Civil Engineers (7) and the default gust velocity is based on an International Electrotechnical Commission (IEC) 64100 Class II site, which has an extreme 50 -year wind gust of $59.5 \mathrm{~m} / \mathrm{s}$. The magnitude of the lateral load of the lateral load from the $\mathrm{j}^{\text {th }}$ component of rotor nacelle assembly (RNA) is derived using a similar approach and is equal to:

$$
F_{R N A, j}=\frac{\rho * C_{d, j} * A_{f, j} * V^{2}}{2} * \text { multiplier } r_{\text {rotor }}
$$

where $\rho$ is the density of air (assumed to equal $1.225 \mathrm{~kg} \mathrm{~m}^{-3}$ ), $C_{d, j}$ is the coefficient of drag for the $\mathrm{j}^{\text {th }}$ component of the RNA, $A_{f, j}$ is the surface area of the $\mathrm{j}^{\text {th }}$ component of the RNA, multiplier ${ }_{\text {rotor }}$ is the rotor's drag multiplier, and $V$ is the velocity of an extreme 50-year wind gust in $\mathrm{m} / \mathrm{s}$. As above, the default gust velocity is based on an IEC 64100 Class II site, which has an extreme 50 -year wind gust of $59.5 \mathrm{~m} / \mathrm{s}$.

The total lateral force (in $\mathrm{N}$ ) is equal to:

$$
F_{\text {lateral,calc }}=\sum_{i=1}^{c t} F_{\text {tower }, i}+\sum_{j=1}^{c r} F_{R N A, j}
$$

where $F_{\text {tower }, i}$ is given by Eq. 12 and $F_{R N A, j}$ is given by Eq. 14 .

The total governing moment, $M_{\text {gov,calc }}(\mathrm{in} \mathrm{N} \cdot \mathrm{m}$ ), is then given by:

$$
M_{\text {gov }, \text { calc }}=\sum_{i=1}^{c} F_{\text {lateral }, i} * Z_{i}
$$

where $F_{\text {lateral }, i}$ is given by Eq. 12 above and $z_{i}$ is the height of the center of mass of the $\mathrm{i}^{\text {th }}$ component in meters. For the overturning moment and lateral loads, we compared the calculated loads above to the loads that could be generated based on the turbine's rated thrust and used the largest of these two values: 


$$
\begin{aligned}
& M_{\text {gov }}=\max \left(M_{\text {gov }, \text { calc }}, F_{\text {lateral,rated }}{ }_{\text {thrust }} * H\right) \\
& F_{\text {lateral }}=\max \left(F_{\text {lateral,calc }}, F_{\text {lateral,rated }} \text { thrust }\right)
\end{aligned}
$$

where the calculated values are given by Eqs. 15 and 16, $F_{\text {lateral,rated }}$ thrust is the force generated based on the turbine's rated thrust (in the default case, we assume this value is equal to $742 \mathrm{kN}$ ), and $H$ is the hub height of the turbine. While we recognize that the method described above does not fully capture the loads used for engineering a foundation design, we plan to refine this approach to add load factors that will better align the results with empirical data from industry.

In Step 2, the foundation design loads are used to estimate the foundation size for the idealized cylindrical spread-foot foundation. ${ }^{3}$ Although additional consideration should be given to sites with high groundwater (buoyancy), seismic loads, soft soils, fatigue loads, local building codes, and sites with higher than the reference site wind speeds, these factors are not included in LandBOSSE 2.1.

To estimate the foundation size, we use the foundation design loads determined in Step 1 to evaluate the necessary foundation radius needed to prevent four types of failure modes: gapping, bearing pressure, slipping, and overturning moment. For all these calculations, we assume the foundation design is cylindrical and the default depth is $3 \mathrm{~m}$ (users may instead specify their own foundation depth, if desired). We then choose the maximum foundation radius determined across all four of these failure modes and evaluate the foundation size.

The following equations are derived from DNV/Riso's Guidelines for Design of Wind Turbines (8) and the Federal Highway Administration's Geotechnical Engineering Circular No. 6 Shallow Foundations (9). The minimum foundation radius required to prevent gapping, $R_{\text {gapping }}$, is given by:

$$
\begin{gathered}
R_{\text {gapping }} \leq 3 e\left(R_{\text {gapping }}\right) \\
e(r)=\frac{M_{\text {gov }}}{V(r)}
\end{gathered}
$$

where $e(r)$ is the eccentricity of the load, which is a function of the foundation radius, $r$ (in m); $e\left(R_{\text {gapping }}\right)$, is given by plugging $R_{\text {gapping }}$ into Eq. 20 ; the governing moment, $M_{\text {gov }}$, is given by Eq. 17; and the total vertical force as a function of $r, V(r)$, is described by Eq. 9 .

The minimum foundation radius to prevent exceeding the bearing pressure, $R_{\text {bearing }}$, is found by solving:

$$
P_{\text {bearing }} * A_{\text {eff }} \geq V\left(R_{\text {bearing }}\right)
$$

\footnotetext{
${ }^{3}$ Note that the model only considers this type of idealized spread-foot foundation. Foundations such as rock anchors, monopiles, pile and cap, and other foundations may be more appropriate depending on soil and rock types or labor and material costs at a particular location. However, LandBOSSE 2.1 does not calculate costs for these other types of foundations.
} 


$$
\begin{gathered}
A_{\text {eff }}=2 *\left[R_{\text {bearing }}{ }^{2} * \operatorname{acos}\left(\frac{e_{R_{\text {bearing }}}}{R_{\text {bearing }}}\right)-e * \sqrt{R_{\text {bearing }}{ }^{2}-e_{R_{\text {bearing }}}{ }^{2}}\right] \\
e_{R_{\text {bearing }}}=e\left(R_{\text {bearing }}\right)
\end{gathered}
$$

where $P_{\text {bearing }}$ is the bearing pressure of the soil (in $\mathrm{N} \mathrm{m}^{-2}$; default value is assumed to be $\left.244,200 \mathrm{kN} \mathrm{m}^{-2}\right) ; V\left(R_{\text {bearing }}\right)$, is given by plugging $R_{\text {bearing }}$ into Eq. 9 ; and the eccentricity based on $R_{\text {bearing }}, e_{R_{\text {bearing }}}$, is given by plugging $R_{\text {bearing }}$ into Eq. 20 .

The minimum foundation radius required to withstand slipping is found by solving:

$$
S F_{\text {slipping }} * F_{\text {lateral }} \leq V\left(R_{\text {slipping }}\right) * \tan \delta
$$

where $S F_{\text {slipping }}$ is the safety factor for slipping (assumed to be 1.5 ), $F_{\text {lateral }}$ is given by Eq. 18 above, $V\left(R_{\text {slipping }}\right)$ is evaluated by plugging $R_{\text {slipping }}$ into Eq. 9 , and $\delta$ is the friction angle of the soil, which is highly variable based on soil type. In LandBOSSE 2.1, we assume the soil is a silty gravel or silty sandy gravel (Unified Soil Classification System class GM) with a friction angle of $25^{\circ}(9)$.

The minimum foundation radius required to withstand the overturning moment, $R_{\text {overturn }}$, is found by solving:

$$
\begin{gathered}
S F_{\text {overturn }} \leq \frac{M_{\text {restoring }}}{M_{\text {overturning }}} \\
M_{\text {restoring }}=V\left(R_{\text {overturn }}\right) * R_{\text {overturn }} \\
M_{\text {overturning }}=M_{\text {gov }}+F_{\text {lateral }} * D
\end{gathered}
$$

where $S F_{\text {overturn }}$ is the safety factor for overturning (assumed to be 1.5$) ; V\left(R_{\text {overturn }}\right)$ is evaluated by plugging $R_{\text {overturn }}$ into Eq. 9; the governing moment, $M_{\text {gov }}$, is given by Eq. 17 ; $F_{\text {lateral }}$ is given by Eq. 18; and $D$ is the depth of the foundation (user input; default is assumed to be $3 \mathrm{~m}$ based on industry experience).

The foundation design radius, $r$ (in $\mathrm{m}$ ), is then equal to:

$$
r=\max \left(R_{\text {overturn }}, R_{\text {slipping }}, R_{\text {bearing }}, R_{\text {gapping }}\right)
$$

where the overturn, slipping, bearing, and gapping radii are given by the equations above.

In Step 3, the quantity of materials is determined based on the foundation size. The excavated volume, $V_{\text {excavated }}$, is given by:

$$
V_{\text {excavated }}=\pi(r+0.5)^{2} * D
$$

where $r$ is the foundation radius given by Eq. 28 and $D$ is the depth of the foundation (user input; default is assumed to be $3 \mathrm{~m}$ based on industry experience). The excavated volume is calculated 
with the assumption that an additional $0.5 \mathrm{~m}$ of space must be excavated beyond the actual foundation radius in order to satisfy the Occupational Safety and Health Administration space requirements for workers during foundation construction activities. The volume of foundation materials, $V_{\text {foundation, }}$, is given by

$$
V_{\text {foundation }}=\pi r^{2} * D * 0.45
$$

where $r$ is the foundation radius given by Eq. 28, $D$ is the depth of the foundation (user input; default is assumed to be $3 \mathrm{~m}$ based on industry experience), and the 0.45 factor accounts for the fact that a portion of the foundation is composed of concrete and steel (the other portion is backfill).

Based on industry data from several constructed spread-foot foundations in the United States, typical spread-foot foundation steel volumetric quantities are between $0.8 \%$ and $1.6 \%$ for 1.5 MW to 3-MW turbines. As a result, we assume concrete comprises $98.5 \%$ of the foundation volume and steel comprises $1.2 \%$ of the foundation volume. We compute the material quantities for steel and concrete based on these assumptions in combination with the foundation volume in Eq. 30.

In Step 4, adjusted RSMeans or industry data on labor and equipment operation rates are combined with the foundation size to determine the operation time for foundation construction associated with the $\mathrm{j}^{\text {th }}$ material (in days), $O T_{F, j}$, which is given by:

$$
O T_{F, j}=\frac{Q_{j}}{T_{j}}
$$

where $Q_{j}$ is the quantity of the $\mathrm{j}^{\text {th }}$ material needed to construct the foundation (units vary depending on the material type; for example, concrete is measured in cubic yards), which is a function of the volume of the foundation given in Eq. 17, and $T_{j}$ is the daily throughput of a crew to construction a unit of the $\mathrm{j}^{\text {th }}$ material.

To calculate the potential for a wind delay in Step 5, we input the operational time and a critical wind speed and height (assumed to be $15 \mathrm{~m} / \mathrm{s}$ at $10 \mathrm{~m}$ for foundation construction) into the WeatherDelay module to estimate the potential wind delays that might occur during each operation of foundation construction. Details can be found in Section 4.1.5.

In Step 6, we calculate the total foundation costs by joining the FoundationSize costs and WeatherDelay costs with the costs for labor and equipment. We then multiply the labor and equipment fuel prices by the foundation volume and the weather delay factor to get the total labor and equipment costs. We assume a per diem rate of $\$ 144 /$ day for all days of operation and add one day of per diem per week of operation because workers only work six days of the week but are paid for seven days of per diem. We also calculate the total material cost using the material prices and the material quantities determined in Step 3, and we estimate that mobilization costs will add an extra $10 \%$ to the total foundation costs.

Finally, in Step 7, we join these summed foundation costs to get the total cost for foundation construction. 


\subsubsection{ErectionCost}

We implement the ErectionCost module using the highlighted structure in Figure 13. Because of data restrictions or other constraints, we are unable to implement all the ideal inputs and calculated parameters. However, we attempt to either (1) use proxy inputs when the needed data are unavailable (e.g., tower component data and crane specifications are used as a proxy for tower technology type) or (2) implement a calculated parameter as a user input (e.g., weather) rather than derive the data directly from the higher-level input (e.g., region).

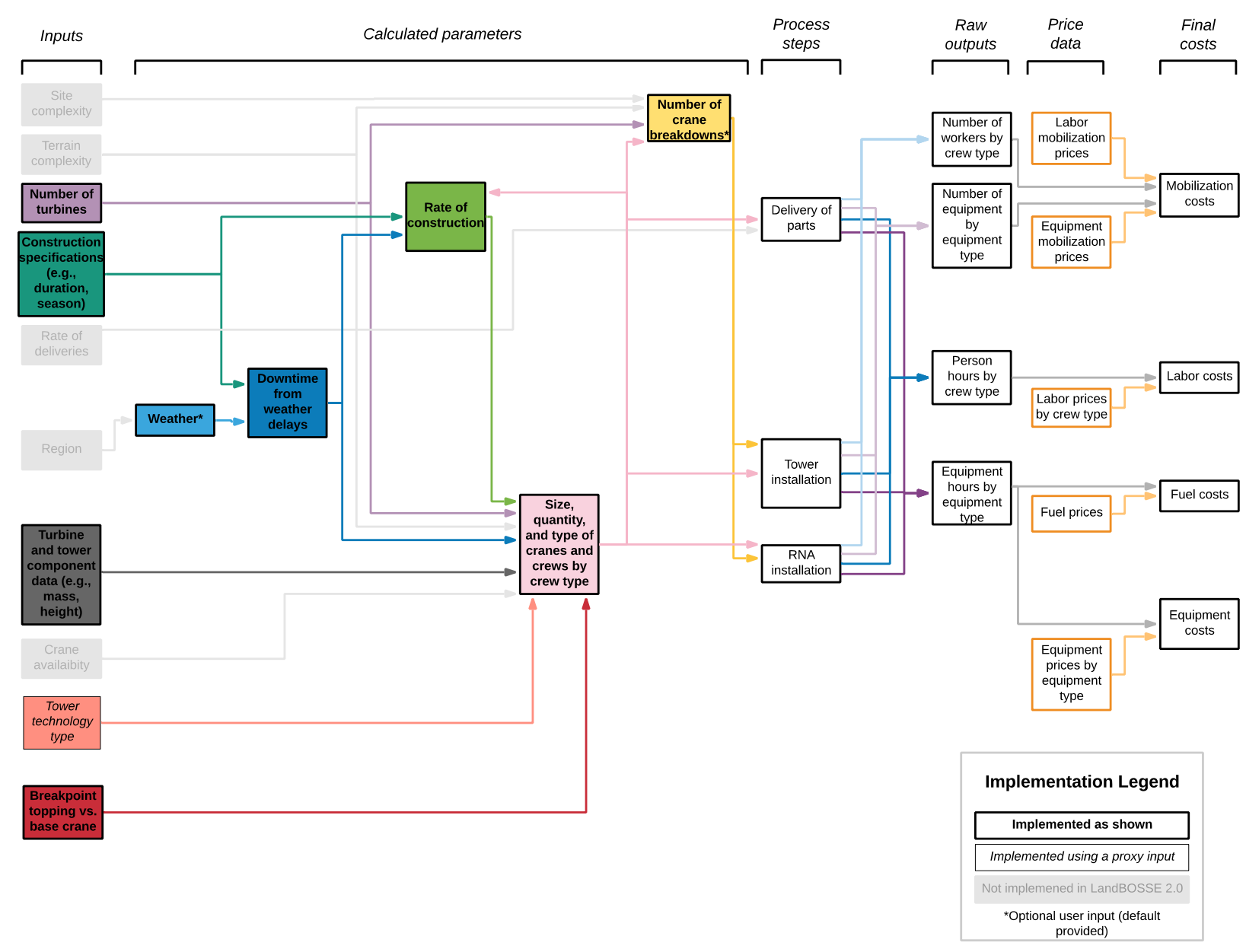

Figure 13. Implementation of ErectionCost module in LandBOSSE 2.1

Proxy inputs are listed in the appendix.

As shown in Figure 13, the general structure of the Erection module includes:

1. Evaluating the operation time associated with using each type of crane input by the user

2. Determining the additional time for wind delays using the WeatherDelay module

3. Calculating the total erection costs for each crane, including the wind delays

4. Choosing the least cost crane.

Each of these calculations is detailed below. 
In Step 1, the operational cycle time and critical wind speed for lifting each component are calculated for all cranes that can lift the component. The required lift height and component mass are compared against the crane specifications for hook height and lift capacity to ensure the specified component can be lifted by a given crane. If the crane can lift the component, the cycle time for crane $C$ lifting component $q\left(C T_{C, q}\right.$ in hours) is computed as:

$$
C T_{C, q}=\frac{h_{q}}{H_{C} * \frac{60 \text { minutes }}{\text { hour }}}+\mathrm{T}_{q}
$$

where $h_{q}$ is the height (in m) to which component, $q$, must be lifted; $H_{C}$ is the hoist speed of the crane ( $\mathrm{m} / \mathrm{min}$ ); and $\mathrm{T}_{q}$ is the cycle time (hours) needed to prepare component $q$ for erection. The critical wind speed $(\mathrm{m} / \mathrm{s})$ for lifting component $q$ with crane $C\left(V_{\text {critical,C, } q}\right)$ is given by:

$$
V_{\text {critical }, C, q}=V_{\max , C} \sqrt{\left(\frac{1.2 m_{q}}{A_{q} * C_{d, q}}\right)}
$$

where $V_{\max , C}$ is the max wind speed (m/s) used to develop the crane load data; 1.2 is a constant ( $\mathrm{m}^{2} /$ metric ton), $m_{q}$ is the mass of component, $q$, in metric tons; $A_{q}$ is the surface area of component $q\left(\mathrm{~m}^{2}\right)$; and $C_{d, q}$ is the coefficient of drag associated with component $q$ (unitless) (10). The surface area, coefficient of drag, and mass for each component are obtained from a table of component properties.

The total operation time (hours) for each crane, $O T_{C}$, is calculated as:

$$
O T_{C}=N_{t} * \sum_{i=1}^{n} C T_{C, q_{i}}
$$

where $N_{t}$ is the number of turbines for the project; $n$ is the number of components; and $C T_{C, q_{i}}$ is the cycle time (hours) for the $i^{\text {th }}$ component being lifted by crane $C$, which is calculated using Eq. 32 (1).

In Step 2, for each crane and component combination, we input the operational time and the critical wind speed into the WeatherDelay module to estimate the potential wind delays that might occur based on historical hourly wind speed measurements. Details can be found in Section 4.1.5.

In Step 3, we calculate the total erection costs for each crane by joining the operational time and weather delays for each crane with the associated prices for labor, equipment, and fuel. Labor costs include the labor associated with each process as well as site management costs specific to the erection scope. We then multiply the labor, equipment, and fuel prices by the operational time to get the costs for each crane and sum theses costs over all the components to get the labor, equipment, and fuel costs for each crane. Finally, we join these summed crane costs with the mobilization costs to get the total costs for erection using each crane.

In Step 4, we use the matrix of cost data from Step 3 to find the crane that has the minimum cost for erecting the components input by the user. The outputs from the erection model include the labor, equipment, fuel, and mobilization costs associated with the least-cost erection strategy. 
The ErectionCost module could be expanded to determine the most cost-effective breakpoint between base and topping cranes and crews.

\subsubsection{CollectionCost}

We implement the collection system cost (CollectionCost) module using the highlighted structure in Figure 14. Because of data restrictions or other constraints, we are unable to implement all the ideal inputs and calculated parameters. However, we attempt to either (1) use proxy inputs when the needed data are unavailable (e.g., interconnect voltage is used a proxy input for turbine model) or (2) implement a calculated parameter as a user input (e.g., weather) rather than derive the data directly from the higher-level input (e.g., region).

As shown in Figure 14, the general structure of the CollectionCost module includes:

1. Creating an array system which estimates the length of each cable, cost of each cable type, and number of array cable strings
A. Calculating rated power capacity of a cable
B. Calculating the number of turbines per cable in a string
C. Calculating the length of each string

2. Determining total trench length required for laying cables based on array system

3. Estimating operation time based on trench length

4. Determining the additional time for weather delays for collection system construction

5. Estimating the labor, material, and equipment costs based on total trench length, length of each cable type, operational time, and additional time for weather delays for collection system construction; this includes labor for cable terminations and splices.

6. Calculating the total collection system cost.

Each of these calculations is detailed below. 


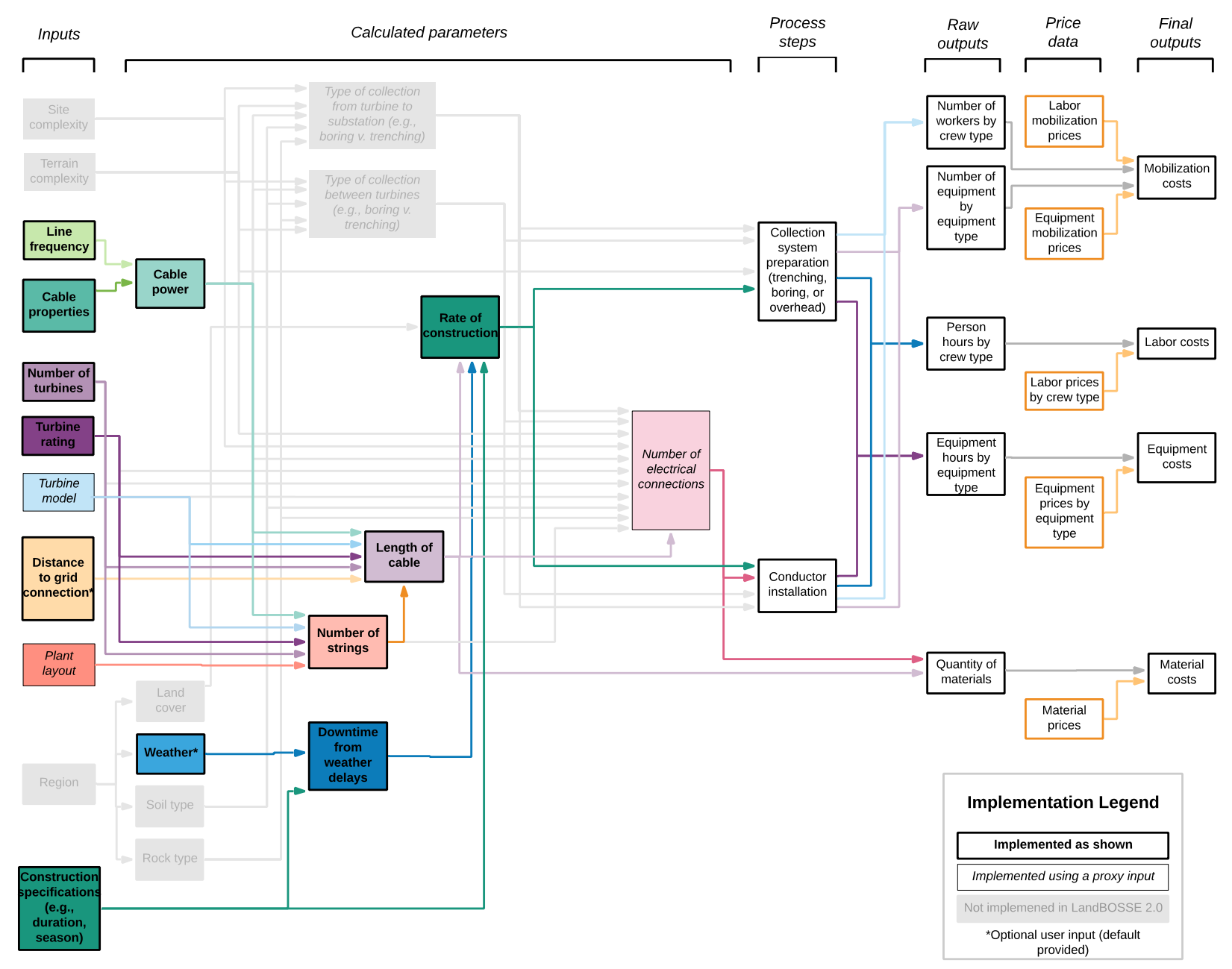

Figure 14. Implementation of CollectionCost module in LandBOSSE 2.1

Proxy inputs are listed in the appendix.

In Step 1.A, the rated power capacity of each user input cable type is calculated. The total power transmission for a balanced three-phase AC power line (12) is given by:

$$
P_{\text {cable }}=\sqrt{3} V_{L L} I \cos \phi
$$

where $V_{L L}$ is the line-to-line voltage (typically specified on a power cable data sheet), $I$ is the total current, and $\cos \phi$ is the power factor. The power factor is a function of the phase angle, $\phi$, which is given by

$$
\phi=\operatorname{atan}\left(\frac{X_{L}}{R}\right)
$$

where $X_{L}$ is the reactance (in ohms) and $R$ is the resistance (in ohms).

In Step 1.B, the number of turbines that the smallest cable on each string can support is given by:

$$
N_{\text {turb,upstream }}=\text { floor }\left(\frac{P_{\text {cable,smallest }}}{P_{\text {turbine }}}\right)
$$


Because the power generation from the turbines on the smallest cable must also be transmitted through subsequent "downstream" cables, the number of turbines supported by each downstream cable is given by:

$$
N_{\text {turb, downstream }}=\text { floor }\left(\frac{P_{\text {cable }}}{P_{\text {turbine }}}-N_{\text {turb, upstream }}\right)
$$

where $P_{\text {cable }}$ is given by Eq. (35), $P_{\text {turbine }}$ is the power rating of the turbine, and $N_{\text {turb,upstream }}$ (the number of upstream turbines on a string) is given by Eq. 37.

Given the number and spacing of turbines on a string, the length of a string is calculated in Step 1.C:

$$
L_{\text {string }}=\sum_{i}^{\text {CableTypes }}\left(N_{\text {turb }_{i}}+\gamma_{i}\right) *\left(l_{\text {turb }} * D_{\text {rotor }}\right)
$$

where $l_{\text {turb }}$ is the spacing between turbines, $D_{\text {rotor }}$ is the rotor diameter, $\gamma_{i}$ is an adder that takes the value of -1 for the first cable type in a string and a value of 0 otherwise. The $\gamma_{i}$ adder is to account for the fact that the first turbine on the smallest cable in a string does not have an associated upstream length of cable.

Cumulative "homerun" distance for all strings can be specified as either a user-defined input or a calculated value in LandBOSSE. Calculated total homerun length is the distance of the largest cable of each string to the substation. The substation placement in the model depends on the number of strings in the array. For an even number of strings, the substation is centered between middle two strings. And for an odd number of strings, the substation is centered on the middle string. The hypotenuse-length calculation of each string is then a simple implementation of the Pythagorean theorem (Figure 15) where the perpendicular distance to substation is equal to the user-defined turbine spacing (expressed in terms of rotor diameter). Note that the sample array design shown in Figure 15 is for illustrative purposes only and is not representative of a specific layout used in the model.

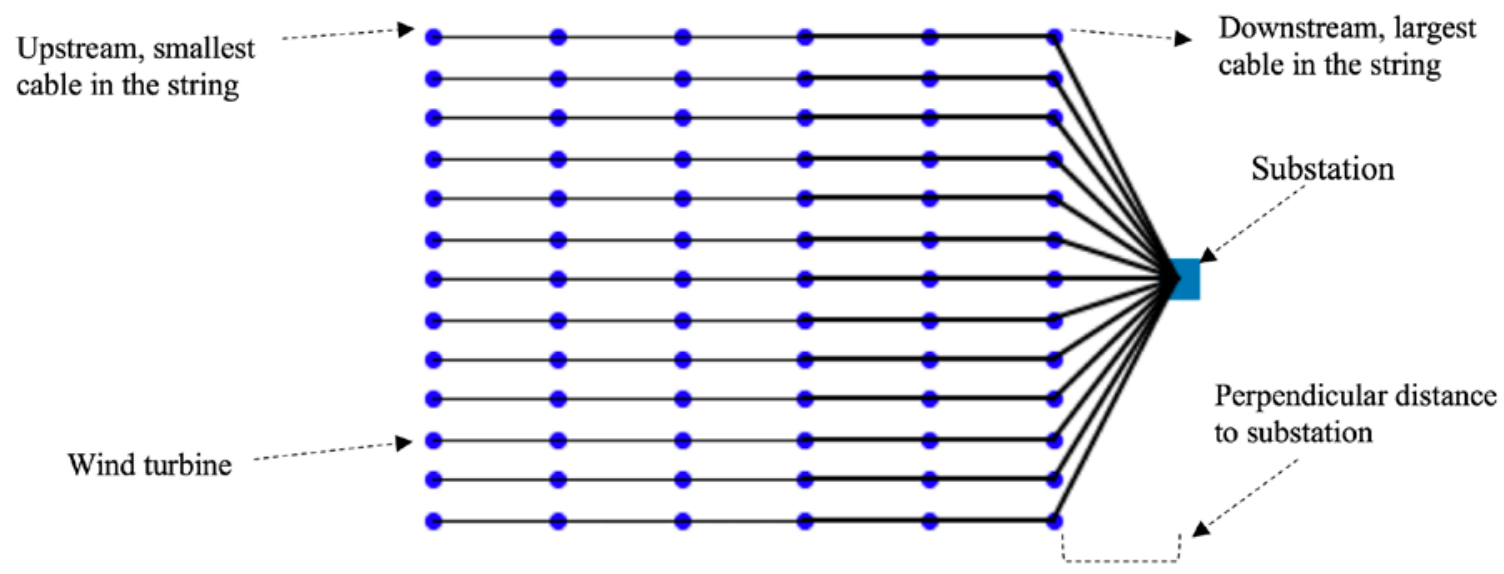

Figure 15. Sample array design used in LandBOSSE for trench length calculation

The array layout shown here is for illustrative purposes only and is not representative of specific layout used in the model. LandBOSSE 2.1 does not accommodate specific layout designs. 
In Step 2, the total array trench length (total length of trenching required to bury the cables underground) is a function of the number of strings, length of each string, and total homerun distance and is given by:

$$
L_{\text {trench }}=L_{\text {string }} * N_{\text {string }}+\sum_{i}^{\text {string }} L_{\text {homerun }}
$$

The total array cable length for a three-phase power line is three times the trench length and is given by:

$$
L_{\text {cable }}=3 * L_{\text {trench }}
$$

In Step 3, adjusted RSMeans, industry, or user-defined data on labor and equipment operation rates are combined with the total trench length to determine the operation time (OT collection $)$ required for constructing the collection system before wind delays. This is given by:

$$
O T_{\text {collection }}=\frac{L_{\text {trench }}}{T_{\text {collection }}}
$$

where $L_{\text {trench }}$ is the total trench length required by the project for laying underground cables and $T_{\text {collection }}$ is the daily output (linear-feet/day) for collection system related operations, which includes clearing the trenching area, grubbing, digging the trench, placing cables, backfilling, and reseeding the trenched area.

In Step 4, weather-related delays are factored in to estimate the additional time that will be required to complete construction of the project's collection system within the user-specified construction time. The calculation of weather-based construction delays is described in Section 4.1.5.

In Step 5, we calculate the total collection system costs by joining the trench length and weather delay data with the costs for labor and equipment. We then multiply the labor and equipment prices by the total trench length and weather delay factor to get the total labor and equipment costs. Labor costs include the labor associated with each process as well as site management costs specific to the erection scope. The total material cost $\left(\operatorname{Cost}_{\text {material }}\right)$, which is the total cumulative cost of all cables used, is calculated by:

$$
\text { Cost }_{\text {material }}=\sum_{i}^{\text {CableTypes }} L_{i} * \operatorname{Cost}_{\text {unit }, \text { cable }, i}
$$

where, $L_{i}$ is the total length of each cable type in the array and Cost $_{\text {unit,cable, } i}$ is the cost per unit of each unique cable type.

Finally, in Step 6, we join these summed collection costs with the mobilization costs to get the total costs for collection system construction.

\subsubsection{WeatherDelay}

To calculate the potential for a wind delay for an operation, we first filter the weather data using the construction time (i.e., time of year and duration of construction) and the hours of operation ("normal" [8 a.m. to 6 p.m.] or "long [24-hour]). We then use the operational time for the type of 
construction, $O T$, to filter the weather window for the portion of construction time of interest for the operation. If $O T$ is greater than the duration allowed for that aspect of construction (e.g., site preparation), we set the weather window to the duration allowed for that part of construction.

Using the weather data in the calculated weather window of interest, we determine the number of wind delays and the duration of each delay for a given operation by assessing when and for how long the wind data exceeds a critical wind speed at a specified height as input by the user. (For site preparation and foundations, we assume the critical wind speed is $15 \mathrm{~m} / \mathrm{s}$ at $10 \mathrm{~m}$; for erection, the crucial wind speed and height vary depending on the crane being used and the part being lifted.) We then use the list of wind delays to estimate the average amount of time the operation would be delayed over the entire operational window. The WeatherDelay module is used by the CollectionCost, ErectionCost, FoundationCost, and SitePreparationCost modules to calculate a list of delays associated with each operation in these modules.

Within each of the modules, a wind delay factor is calculated from the list of wind delays. This happens in two steps. For the first step, all wind delays of four hours or longer are transformed into delays of ten hours. This codifies an assumption that construction delays longer than four hours shut down operations for an entire day. For the second step, we obtain the wind delay factor, $D_{\text {wind }}$ by:

$$
D_{\text {wind }}=\frac{\sum_{i=1}^{k} D_{\text {shutdown }}}{O T}
$$

where $D_{\text {shutdown }}$ is the number of hours the construction will halt because of a period of wind speed exceeding the critical wind speed, $O T$ is the operational time in hours of construction, and $k$ is the total number of shutdowns in the original wind delay list calculated by the WeatherDelay module.

After it is calculated, $D_{\text {wind }}$ is used as a multiplier for labor costs or construction time to obtain total costs or total time anticipated by the delay. For example, given labor cost $L$ before weather delay and $D_{\text {wind }}$, the total labor cost $C$ is obtained by:

$$
C=L \frac{1}{1-D_{\text {wind }}}
$$

\subsection{Empirical Modules}

Because of data limitations or other constraints, four of the LandBOSSE 2.1 modules are implemented using curve fits of industry data DevelopmentCost, ManagementCost, GridConnectionCost, and SubstationCost. The sections that follow detail the implementation of each of these modules.

\subsubsection{DevelopmentCost}

For the DevelopmentCost module, we do not implement the detailed process diagram in Figure 16 , because obtaining data for most of the inputs was outside the scope of this work and the contribution of development costs to the total BOS costs is small compared to the cost in other 
modules. ${ }^{4}$ For now, the development costs are input by the user directly and do not vary based on project size (Figure 16). As more data become available, site development costs could be refined to include more-detailed inputs and calculated parameters.

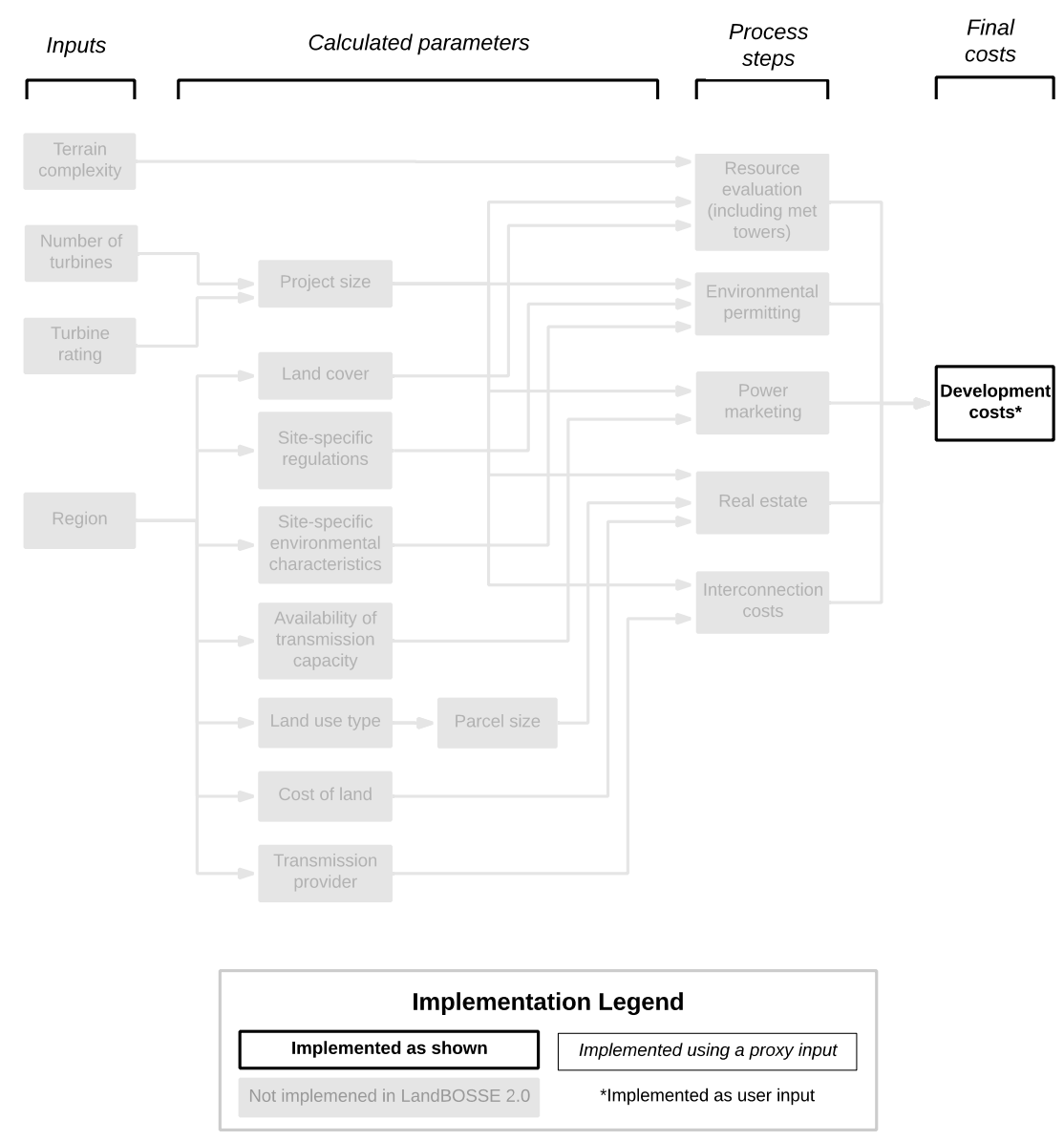

Figure 16. Implementation of DevelopmentCost module in LandBOSSE 2.1

Proxy inputs are listed in the appendix.

\subsubsection{ManagementCost}

We implement the ManagementCost module using the general structure outlined in Section 2.2, and we make a few minor modifications to accommodate data limitations and other restrictions (see Figure 17). For example, certain parameters are not implemented in LandBOSSE 2.1 (e.g., region and soil type), and other parameters are implemented using a proxy input (e.g., mark-up and contingency constants are used as proxies for builder size and the number of highway permits is used as a proxy for a site-specific interface with public infrastructure).

\footnotetext{
${ }^{4}$ Based on proprietary data from industry, typical development costs comprise less than $10 \%$ of total BOS costs.
} 


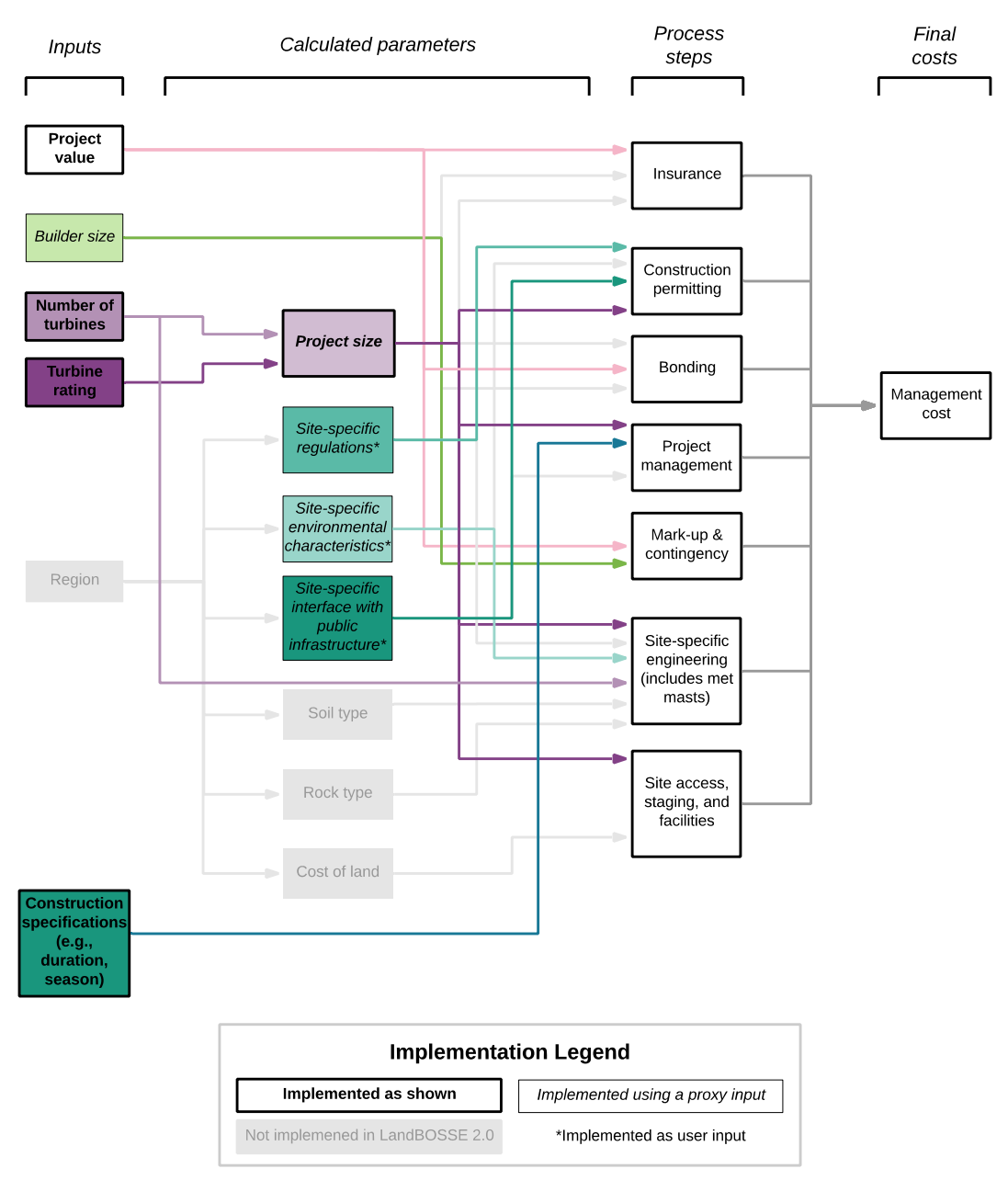

Figure 17. Implementation of ManagementCost module in LandBOSSE 2.1

Proxy inputs are listed in the appendix.

In general, the ManagementCost module includes:

1. Evaluating the insurance costs based on the project value

2. Determining cost of construction permitting based on the foundation cost

3. Calculating the bonding costs based on the project value

4. Estimating the project management costs based on the construction time

5. Evaluating the mark-up and contingency costs based on the project value

6. Calculating the site-specific costs for engineering the foundation and collection systems and installing measurement towers with meteorological equipment (met masts)

7. Estimating the costs for developing site facilities required for site access and staging, including infrastructure for construction management at the laydown yard (e.g., electrical hook-up for site trailers, restroom facilities, cattle guards, site security, batch plant, construction of site offices, monthly office costs, and project signage).

Each of these calculations is detailed below. 
The total management costs, $C_{M}$, (in USD) are given by:

$$
C_{M}=C_{I}+C_{P}+C_{B}+C_{P M}+C_{M C}+C_{E}+C_{S}
$$

where $C_{I}$ is the insurance cost, $C_{P}$ is the permitting cost, $C_{B}$ is the bonding cost, $C_{P M}$ is the project management cost, $C_{M}$ is the mark-up and contingency cost, $C_{E}$ is the site-specific engineering cost, and $C_{S}$ is the cost of developing site facilities for construction management at the laydown yard (including met masts). All these subtypes of management costs are derived by fitting curves to proprietary industry data. The insurance cost, $C_{I}$, is given by:

$$
C_{I}=0.0056 * V_{p}
$$

where $V_{p}$ is the value of the project (in USD), which is equal to the sum of the costs from the other modules (total costs except management). The construction permitting cost, $C_{P}$, is given by:

$$
C_{P}=0.02 * C_{F}+20,000 * N_{h}
$$

where $C_{F}$ is the cost of the foundation (in USD) and $N_{h}$ is the number of highway permits required for the project (user input). The bonding cost, $C_{B}$, is given by:

$$
C_{B}=0.01 * V_{p}
$$

where $V_{p}$ is the value of the project (in USD). The project management cost is given by:

$$
C_{P M}= \begin{cases}\left(53.33 * C T^{2}-3442 * C T+209,542\right) *(C T+2) & \text { if } C T<28 \text { months } \\ 155,000 *(C T+2) & \text { if } C T \geq 28 \text { months }\end{cases}
$$

where $C T$ is the construction time (in months). The project mark-up and contingency cost, $C_{M C}$, is given by:

$$
C_{M C}=c * V_{p}
$$

where $V_{p}$ is the value of the project (in USD), and $c$ is the sum of the following user-specified inputs:

$$
c=c_{m c}+c_{m w}+c_{s t}+c_{m o}+c_{p m}
$$

where $c_{m c}$ is the markup contingency (\%), $c_{m w}$ is the markup warranty management (\%), $c_{s t}$ is the sales and use tax (\%), $c_{m o}$ is the markup overhead (\%), and $c_{p m}$ is the markup profit margin $(\%)$.

The engineering cost, $C_{E}$, is given by:

$$
C_{E}=C_{e n g}+C_{m e t}
$$




$$
\begin{gathered}
C_{\text {eng }}=\left\{\begin{array}{c}
\left(7188.5 * N_{t}\right)+\left(3.4893 * \ln \left(N_{t}\right)-7.3049\right) *(16,800)+165,675 \quad \text { if }(P S)<200 \\
\left(7188.5 * N_{t}\right)+\left(3.4893 * \ln \left(N_{t}\right)-7.3049\right) *(16,800)+327,250 \quad \text { if }(P S) \geq 200
\end{array}\right. \\
C_{m e t}=N_{\text {perm }_{\text {met }}} * M_{\text {perm }} \text { met } \\
P S
\end{gathered}
$$

where $C_{e n g}$ is the development engineering cost for foundations and collection system, $C_{m e t}$ is the cost for met masts, $N_{t}$ is the number of turbines, $P S$ is the project size (given by Eq. 56) $R_{t}$ is the turbine rating (in megawatts $[\mathrm{MW}]$ ), and the number of permanent met masts $\left(N_{\text {perm }}\right)$ and temporary met masts $\left(N_{\text {temp }}\right)$ are given in Table 2 and their corresponding multipliers are in Table 3.

Table 2. Number of Met Masts by Project Size

\begin{tabular}{ccc}
\hline $\begin{array}{l}\text { Project Size } \\
(\mathbf{M W})\end{array}$ & $\begin{array}{l}\text { Number of } \\
\text { Permanent Met } \\
\text { Masts }\left(\boldsymbol{N}_{\text {perm }} \text { met }\right)\end{array}$ & $\left.\begin{array}{l}\text { Number of } \\
\text { Temporary Met } \\
\text { Masts }\left(\boldsymbol{N}_{\text {temp }} \text { met }\right.\end{array}\right)$ \\
\hline$<30$ & 1 & 1 \\
$30-100$ & 2 & 2 \\
$100-300$ & 2 & 4 \\
$300+$ & Round $(P S / 100)$ & Round $(P S / 100) * 2$ \\
\hline \multicolumn{3}{c}{ Compiled from proprietary industry data; } \\
\multicolumn{2}{c}{ PS is project size, which is given by Eq. 56. }
\end{tabular}

Table 3. Met Mast Multipliers by Hub Height

\begin{tabular}{lcc}
\hline $\begin{array}{l}\text { Hub Height } \\
(\mathrm{m})\end{array}$ & $\begin{array}{l}\text { Multiplier for } \\
\text { Permanent } \\
\text { Met Masts }\end{array}$ & $\begin{array}{l}\text { Multiplier for } \\
\text { Temporary } \text { Met } \\
\text { Masts }\left(\boldsymbol{M}_{\text {temp }} \boldsymbol{p}_{\text {met }}\right.\end{array}$ \\
\hline Below 90 & 232,600 & 92,600 \\
Above 90 & 290,000 & 116,800 \\
\hline
\end{tabular}

Compiled from proprietary industry data;

PS is project size, which is given by Eq. 56 .

Finally, the site facility costs for construction management, $C_{S}$, at the laydown yard are given by:

$$
C_{S}=C_{O M}+C_{C S}
$$

where $C_{O M}$ is the cost of constructing operation and maintenance buildings (given by Eq. 58 below) and $C_{C S}$ is the cost of developing infrastructure for compound security at the laydown yard, including electrical hook-up for site trailers, restroom facilities, cattle guards, site security, batch plant, construction of site offices, monthly office costs, and project signage (given by Eq. 3.2.9, below). 
The cost of constructing operation and maintenance buildings, $C_{O M}$, is given by the following empirical relationship, which was derived from industry data:

$$
C_{O M}=B A * 125+176,125
$$

where $B A$ is the building area in square feet, which is a function of project size (given by Eq. 56) as indicated in Table 4.

Table 4. Size of Operation and Maintenance (O\&M) Facilities by Project Size

\begin{tabular}{rrr}
\hline \multicolumn{2}{c}{$\begin{array}{c}\text { Project Size (MW) } \\
\text { Minimum }\end{array}$} & $\begin{array}{c}\text { O\&M Building Area } \\
\text { (BA, in sq. ft.) }\end{array}$ \\
\hline 0 & 199 & 3,000 \\
200 & 499 & 5,000 \\
500 & 799 & 7,000 \\
800 & 999 & 9,000 \\
$1,000+$ & 4,999 & 12,000 \\
\hline
\end{tabular}

Compiled from proprietary industry data

The cost of developing infrastructure for compound security at the laydown yard, $C_{C S}$, is given by:

$$
C_{C S}=9,825 * N_{R}+29,850 * C T+A_{C S}+60 * P S+62,400
$$

where $N_{R}$ is the number of access roads for the laydown yard, which varies with the number of turbines according to Table 5; $C T$ is the total construction time (in months, which is implemented as a user input); $A_{C S}$ is the cost adder for compound security, which varies with the number of turbines according to Table 5; and PS is the project size given by Eq. 56.

Table 5. Constants for Compound Security by Number of Turbines

\begin{tabular}{clc}
\hline $\begin{array}{l}\text { Number of } \\
\text { Turbines (Nt) }\end{array}$ & $\begin{array}{l}\text { Number of Access } \\
\text { Roads for Laydown } \\
\text { Yard (NR) }\end{array}$ & $\begin{array}{l}\text { Cost Adder for } \\
\text { Compound Security } \\
\text { (ACS, in USD) }\end{array}$ \\
\hline $0-29$ & 1 & 30,000 \\
$30-99$ & Round $\left(0.05^{*}\right.$ NT) & 240,000 \\
$100+$ & Round $\left(0.05^{*}\right.$ NT) & 390,000 \\
\hline
\end{tabular}

Compiled from proprietary industry data

\subsubsection{GridConnectionCost}

We implement the grid connection cost module (GridConnectionCost), which includes transmission and interconnection costs, using a curve fit of empirical data. We are only able to derive a relationship for the total costs associated with substation construction, and we are unable to break down the costs by type (e.g., material versus labor; see Figure 18 for an illustration of implementation of substation costs in LandBOSSE 2.1). 


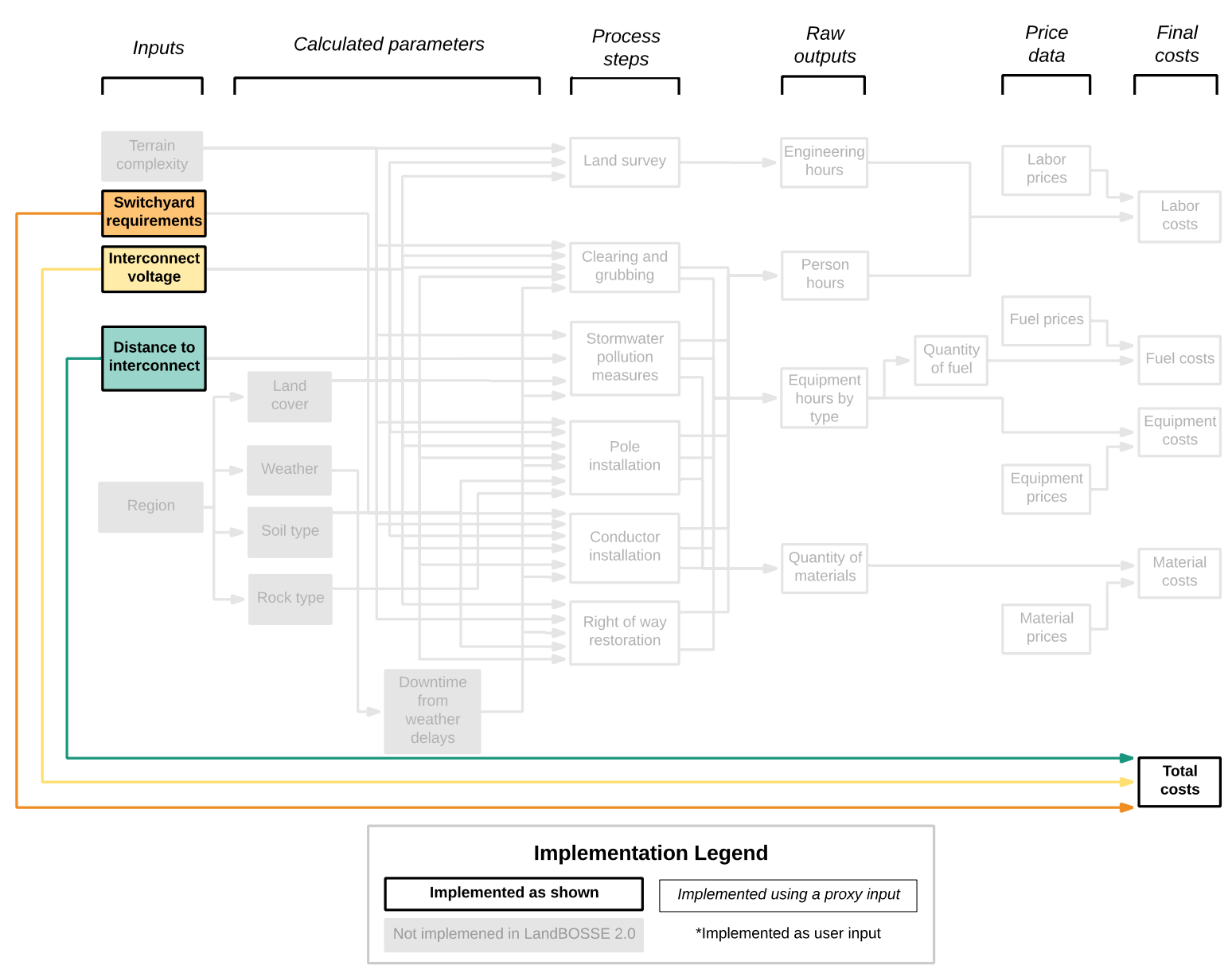

Figure 18. Implementation of GridConnectionCost module in LandBOSSE 2.1

Proxy inputs are listed in the appendix.

We are only able to derive a relationship for the total costs associated with grid connection, and we are unable to break down the costs by type (e.g., material versus labor). Based on a regression analysis of industry data, the grid connection costs, $C_{G C}$, for non-zero distance to interconnection are given by:

$$
C_{G C}=(1,176 V+218,257) D_{i}^{0.8937}+A_{I}
$$

where $V$ is the line, or interconnection, voltage (in $\mathrm{kV}$ ); $D_{i}$ is distance to interconnection (in miles); and $A_{I}$ is an adder for interconnection costs that is driven by the requirements for a new switchyard (if the project requires a new switchyard, $A_{I}=18,115 \mathrm{~V}+165,994$; otherwise $A_{I}=0$ ). Our default assumption is that a new switchyard is required. If the distance to an interconnection is zero, we assume the grid connection costs are zero. Default data are described in the appendix.

\subsubsection{SubstationCost}

We implement the SubstationCost module using a curve fit of empirical data. We are only able to derive a relationship for the total costs associated with substation construction, and we are 
unable to break down the costs by type (e.g., material versus labor; see Figure 19 for an illustration of implementation of substation costs in LandBOSSE 2.1). Based on a regression analysis of industry data, the substation costs, $C_{S}$, are given by:

$$
\begin{gathered}
C_{S}=11,652(V+S)+11,795(S)^{0.3549}+1,526,800 \\
S=N_{t} R_{t}
\end{gathered}
$$

where $V$ is line, or interconnection, voltage (in $\mathrm{kV}$ ); $S$ is the project size; $N_{t}$ is the number of turbines; and $R_{t}$ is the turbine rating (in $\mathrm{MW}$ ). Default data values are described in the appendix.

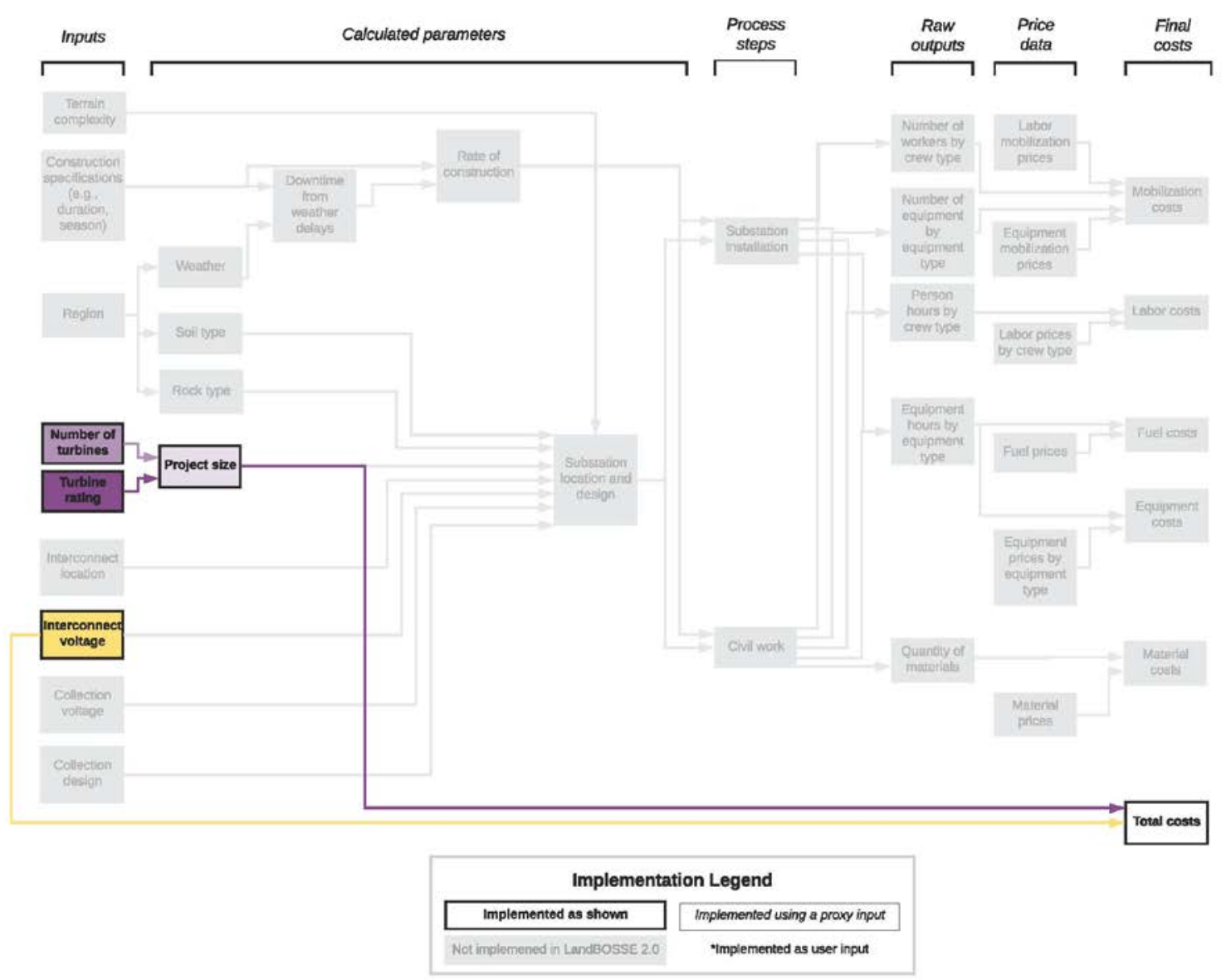

Figure 19. Implementation of SubstationCost module in LandBOSSE 2.1

Proxy inputs are listed in the appendix. 


\section{LandBOSSE Verification}

We engaged with several wind industry BOS contractors to verify our understanding of the wind plant construction processes and practices. Based on industry feedback, we made changes to the structure of the code to reflect current industry practices. We also added capabilities to more accurately capture variations in construction in different regions of the country. We validated the model against proprietary industry data for current construction practices as well as alternative tower and erection technologies. We are unable to provide additional details about the data that were used to verify the model because these data are proprietary.

The validation scenarios included a range of turbine nameplate capacities, rotor diameters, and plant sizes. Cycle times and rates of construction, material quantities, labor fraction, equipment type and number were compared at the module level over a range of turbine and plant sizes. Adjustments were made to the inputs of the model to more accurately reproduce empirical values. However, it is important to note that these scenarios were based on current plant construction practices and technology. Additional validations should be performed by the user to ensure the model generates reasonable results for their scenario(s) of interest, particularly for future technology or construction scenarios (e.g., turbines above $3 \mathrm{MW}$, hub heights greater than $120 \mathrm{~m}$, or alternative erection technologies). 


\section{Conclusion}

The LandBOSSE model allows users to explore how the capital expenditures needed to install a utility-scale, land-based wind plant might change under different innovation scenarios. The model outputs all cost estimates for all operations associated with installing a wind plant. For processed-based modules, which include site preparation, foundation construction, collection system construction, and tower installation, these costs are broken down by type (e.g., labor, material, and equipment) costs. For all other modules (development, management, substation, and grid connection), only total costs are reported. Potential applications could include:

- Examinations of economies of scale for BOS costs with regard to wind plant size and turbine size

- Assessments of alternative BOS technologies, such as foundations, tower technologies, erection technologies, and collection system configurations

- Comparisons of BOS costs for farms with different turbine types and heights

- Estimations of potential costs of repowering.

This report summarizes the approach, methods, and equations used to develop LandBOSSE. The model was developed using a hybrid of process-based and empirically derived methods to create a modular model design that will allow for updates as wind energy technology evolves. The goal of LandBOSSE is to allow researchers, analysts, wind power developers, government agencies, and the public to explore how BOS may vary for different wind plant designs. 


\section{References}

1. U.S. Energy Information Administration. Electricity Generation from Fossil Fuels Declined in 2017 as Renewable Generation Rose. Today in Energy. 2018 [cited 2018 Mar 27]. https://www.eia.gov/todayinenergy/detail.php?id=35412.

2. U.S. Department of Energy Wind and Water Power Technologies Office. Wind Vision: A New Era for Wind Power in the United States. U.S. Department of Energy; 2015 Mar [cited 2018 Mar 27]. DOE/GO-102015-4640. https://www.energy.gov/eere/wind/maps/wind-vision.

3. Moné C, Maples B, Hand M. Land-Based Wind Plant Balance-of-System Cost Drivers and Sensitivities. In Las Vegas, NV; 2014.

4. Christensen P, Dysert L. Cost Estimate Classification System: As Applied in Engineering, Procurement, and Construction for the Process Industries. Association for the Advancement of Cost Engineering. 2005;Recommended Practice No. 18R-97:10.

5. Iberdrola Renewables, LLC. Blue Creek Wind Farm Van Wert County. [cited 2018 Dec 10]. https://www.ccao.org/wp-content/uploads/15\%20sum\%20Wendel\%20Energy.pdf.

6. U.S. Energy Information Administration. Gasoline and Diesel Fuel Update: Energy Information Administration. 2018 [cited 2018 Mar 29]. https://www.eia.gov/petroleum/gasdiesel/.

7. American Society of Civil Engineers (ASCE). Minimum Design Loads for Buildings and Other Structures: ASCE/SEI 7-10. Reston, VA: American Society of Civil Engineers; 2013 [cited 2018 Apr 5]. http://ascelibrary.org/doi/book/10.1061/9780784412916.

8. DNV/Riso. Guidelines for Design of Wind Turbines. Copenhagen, Denmark: Det Norske Veritas; 2002 p. 294.

http://www.homepages.ucl.ac.uk/ uceseug/Fluids2/Wind_Turbines/Codes_and_Manuals/Guideli nes_for_Design_of_Wind_Turbines.pdf.

9. Kimmerling R. Geotechnical Engineering Circular No. 6: Shallow Foundations. Washington, D.C.: Federal Highway Administration; 2002 p. 310. FHWA-SA-02-054. https://www.fhwa.dot.gov/engineering/geotech/pubs/010943.pdf.

10. Liebherr-Werk Ehingen GmbH. Training Documents: Influence of Wind on Crane Operation. Ehingen, Germany: Liebherr-Werk Ehingen GmbH; 2017 p. 56. 4th Edition. https://www.liebherr.com/shared/media/mobile-and-crawler-cranes/brochures/windinfluences/liebherr-influence-of-wind-p403-e04-2017.pdf.

11. Liebherr-Werk Ehingen GmbH. LR Crawler Cranes: Liebherr. 2018 [cited 2018 Mar 29]. https://www.liebherr.com/en/deu/products/mobile-and-crawler-cranes/crawler-cranes/lr-crawlercranes/lr-crawler-cranes.html.

12. Purkait P, Biswas B, Das S, Koley C. Electrical and Electronics Measurements and Instrumentation. 2013 p. 272. 


\section{Appendix: Data Structure for LandBOSSE Inputs}

This appendix documents the data structure for user inputs and default data in LandBOSSE 2.1. It is broken down into three sections: (A.1) proxy inputs and their correspondence to variables in the implementation process diagrams shown in Section 4, (A.2) model inputs that can be modified by the user, (A.3) hard-coded values, and (A.4) inputs and outputs for each module within the model.

\section{A.1 Proxy Inputs}

Table A.1 summarizes the proxy inputs that are used in each module. Refer to the implementation process diagrams in Section 4 for an illustration of how these variables are used in the model.

Table A-1. Proxy Inputs

\begin{tabular}{|c|c|c|}
\hline Module & Name in Process Diagram & $\begin{array}{l}\text { Proxy Variable (Implementation Approach in } \\
\text { LandBOSSE 2.1) }\end{array}$ \\
\hline DevelopmentCost & $\mathrm{n} / \mathrm{a}$ & $\mathrm{n} / \mathrm{a}$ \\
\hline \multirow{3}{*}{ ManagementCost } & Builder size & $\begin{array}{l}\text { Project cost (calculated by model) and markup } \\
\text { constants (hard-coded) }\end{array}$ \\
\hline & Site-specific regulations & $\begin{array}{l}\text { Foundation cost (calculated by model and used to } \\
\text { estimate number of building permits), and number of } \\
\text { highway permits (hard-coded) }\end{array}$ \\
\hline & $\begin{array}{l}\text { Site-specific environmental characteristics } \\
\text { Site-specific interface with public infrastructure }\end{array}$ & $\begin{array}{l}\text { Number of met towers (hard-coded) } \\
\text { Number of access roads (hard-coded) }\end{array}$ \\
\hline \multirow{3}{*}{ SitePreparationCost } & Site complexity & Number of access roads (hard-coded) \\
\hline & Project size & $\begin{array}{l}\text { Operation time required for constructing roads } \\
\text { (calculated by model) }\end{array}$ \\
\hline & Equipment size & Throughput data for operations (user input) \\
\hline FoundationCost & Soil type & $\begin{array}{l}\text { Bearing pressure (user input) and friction angle of soil } \\
\text { (hard-coded) }\end{array}$ \\
\hline ErectionCost & Tower technology type & $\begin{array}{l}\text { List of tower and turbine component data (user input) } \\
\text { and list of crane specifications (user input) }\end{array}$ \\
\hline CollectionCost & Turbine model & $\begin{array}{l}\text { Line frequency (user input) and interconnect voltage } \\
\text { (user input) }\end{array}$ \\
\hline
\end{tabular}




\begin{tabular}{|c|c|c|}
\hline Module & Name in Process Diagram & $\begin{array}{l}\text { Proxy Variable (Implementation Approach in } \\
\text { LandBOSSE 2.1) }\end{array}$ \\
\hline & Plant layout & $\begin{array}{l}\text { Row spacing (user input) and turbine spacing (user } \\
\text { input) }\end{array}$ \\
\hline & Number of electrical connections & $\begin{array}{l}\text { Operation time required for trenching (calculated by } \\
\text { model) }\end{array}$ \\
\hline GridConnectionCost & $\mathrm{n} / \mathrm{a}$ & $\mathrm{n} / \mathrm{a}$ \\
\hline SubstationCost & $\mathrm{n} / \mathrm{a}$ & $\mathrm{n} / \mathrm{a}$ \\
\hline
\end{tabular}

\section{A.2 Summary of Model Inputs}

As shown in Table A-2, there are 11 main types of input data. The data sources for each of these types of input data are provided in Table A-3, and sample data for each of these data types are provided in Tables A-4 through A-14 (Table A-2 lists the table numbers that provide details for each data type). All these data are provided to illustrate default model inputs, and users should modify these values based on their specific project. Refer to the GitHub repository (https://github.com/WISDEM/LandBOSSE) for more information on how to modify these values.

Table A-2. LandBOSSE Input Data

\begin{tabular}{|c|c|c|c|}
\hline Type of Data & Description & Sample Data Table & Relevant Module(s) \\
\hline Project list & List of projects to be executed during model run ${ }^{a}$ & Table A-4 & All modules \\
\hline Components data & Properties of turbine and tower components & Table A-5 & $\begin{array}{l}\text { ErectionCost } \\
\text { FoundationCost }\end{array}$ \\
\hline Cable specs & Specifications for electrical cables & Table A-6 & CollectionCost \\
\hline Equipment data & $\begin{array}{l}\text { List of non-crane equipment types that pair with specific cranes based on } \\
\text { Equipment ID }\end{array}$ & Table A-7 & ErectionCost \\
\hline
\end{tabular}




\begin{tabular}{|c|c|c|c|}
\hline Type of Data & Description & Sample Data Table & Relevant Module(s) \\
\hline Equipment price & List of equipment prices (including crane prices) & Table A-8 & ErectionCost \\
\hline Crane specs & List of crane specifications (including capacity limits and Equipment IDs) & Table A-9 & ErectionCost \\
\hline & & & ErectionCost \\
\hline Crew data & $\begin{array}{l}\text { List of crews for different types of operations (linked to prices and other } \\
\text { tables using Crew ID) }\end{array}$ & Table A-10 & $\begin{array}{l}\text { FoundationCost } \\
\text { SitePreparationCost } \\
\text { CollectionCost }\end{array}$ \\
\hline & & & ErectionCost \\
\hline Crew price & List of prices for crews (linked to crew data by Crew ID) & Table A-11 & $\begin{array}{l}\text { FoundationCost } \\
\text { SitePreparationCost } \\
\text { CollectionCost }\end{array}$ \\
\hline Material price & List of material prices by Material type ID in RSMeans data & Table A-12 & $\begin{array}{l}\text { SitePreparationCost } \\
\text { FoundationCost }\end{array}$ \\
\hline RSMeans & List of throughput, cost, and operation data for various processes & Table A-13 & $\begin{array}{l}\text { SitePreparationCost } \\
\text { FoundationCost } \\
\text { CollectionCost }\end{array}$ \\
\hline Building area & List of site facility building sizes by plant size & Table A-14 & ManagementCost \\
\hline
\end{tabular}

a At least one project must be listed to run LandBOSSE 2.1 . 


\section{Table A.3. Summary of Data Sources}

\begin{tabular}{|c|c|}
\hline Type of Data & Source \\
\hline Project list & $\begin{array}{l}\text { Engineering judgement, knowledge of industry practice, and fuel prices from the } \\
\text { U.S. Energy Information Administration (6) }\end{array}$ \\
\hline Components data & Knowledge of industry practice and publicly available turbine and tower data \\
\hline Cable specs & Knowledge of industry practice and publicly available cable data \\
\hline Equipment data & Knowledge of industry practice \\
\hline Equipment price & Proprietary data from industry \\
\hline Crane specs & Publicly available crane charts from Liebherr (11) \\
\hline Crew data & Knowledge of industry practice \\
\hline Crew price & Proprietary data from industry \\
\hline Material price & $\begin{array}{l}\text { RSMeans Construction Cost Database adjusted with proprietary data from } \\
\text { industry }\end{array}$ \\
\hline RSMeans & RSMeans Construction Cost Database \\
\hline Building area & Knowledge of industry practice \\
\hline
\end{tabular}


Table A-4. Sample Inputs for Project List, Listed by Project ID

\begin{tabular}{|c|c|c|c|c|}
\hline Parameter Name & $\begin{array}{l}\text { GE 1.5-MW, } \\
80 \mathrm{~m} \mathrm{HH}\end{array}$ & $\begin{array}{l}\text { Clipper 2.5-MW, } \\
\text { 80-m HH }\end{array}$ & $\begin{array}{l}\text { IEA }{ }^{\text {a } 3.6-M W, ~} \\
\text { 85-m HH }\end{array}$ & $\begin{array}{l}\text { IEA 3.6-MW, } \\
\text { 120-m HH }\end{array}$ \\
\hline Total project construction time (months) & 9 & 9 & 9 & 9 \\
\hline Turbine rating (MW) & 1.5 & 2.5 & 3.6 & 3.6 \\
\hline Hub height (m) & 80 & 80 & 85 & 120 \\
\hline Rotor diameter (m) & 77 & 96 & 130 & 130 \\
\hline Number of breakdowns per $100 \mathrm{MW}$ & 1 & 1 & 1 & 1 \\
\hline Turbine spacing (times rotor diameter) & 4 & 4 & 4 & 4 \\
\hline Row spacing (times rotor diameter) & 10 & 10 & 10 & 10 \\
\hline Number of sections per tower & 3 & 4 & 4 & 7 \\
\hline Number of RNA picks (at hub height) & 4 & 4 & 4 & 4 \\
\hline Number of turbines & 67 & 40 & 28 & 28 \\
\hline Number of turbines per day & 2 & 2 & 2 & 2 \\
\hline Breakpoint between base and topping (percent) & 0.75 & 0.75 & 0.75 & 0.75 \\
\hline Fuel cost (USD per gallons) & 1 & 1 & 1 & 1 \\
\hline Rate of deliveries (turbines per week) & 10 & 10 & 10 & 10 \\
\hline Wind shear exponent & 0.2 & 0.2 & 0.2 & 0.2 \\
\hline Tower type & steel & steel & steel & steel \\
\hline Foundation depth (m) & 3 & 3 & 1.5 & 3 \\
\hline Rated thrust (kN) & 589 & 1,010 & 1,260 & 1,780 \\
\hline Bearing pressure $\left(\mathrm{N} / \mathrm{m}^{2}\right)$ & 191,521 & 191,521 & 191,521 & 191,521 \\
\hline 50 -year gust velocity $(\mathrm{m} / \mathrm{s})$ & 59.5 & 59.5 & 52.5 & 52.5 \\
\hline Line frequency $(\mathrm{Hz})$ & 60 & 60 & 60 & 60 \\
\hline Combined homerun length to substation (km) & 50 & 50 & 50 & 50 \\
\hline
\end{tabular}

Data for at least one project ID are required to execute all LandBOSSE modules.

a IEA = International Energy Agency 
Table A-5. Sample Turbine and Tower Components Data

\begin{tabular}{|c|c|c|c|c|c|c|c|c|c|c|c|c|}
\hline \multirow[t]{2}{*}{ Component } & \multicolumn{12}{|c|}{ Property Name } \\
\hline & $\begin{array}{l}\text { Mass } \\
\text { (metric } \\
\text { tons) }\end{array}$ & $\begin{array}{l}\text { Lift } \\
\text { Height } \\
\text { (m) }\end{array}$ & $\begin{array}{l}\text { Surface } \\
\text { area }\left(m^{2}\right)\end{array}$ & $\begin{array}{l}\text { Coeff. } \\
\text { Drag }\end{array}$ & $\begin{array}{l}\text { Coeff. Drag } \\
\text { (installed) }\end{array}$ & $\begin{array}{l}\text { Section } \\
\text { Height } \\
\text { (m) }\end{array}$ & $\begin{array}{l}\text { Lever } \\
\text { Arm } \\
\text { (m) }\end{array}$ & $\begin{array}{l}\text { Cycle Time } \\
\text { Installation } \\
\text { (hrs) }\end{array}$ & $\begin{array}{l}\text { Offload } \\
\text { Hook } \\
\text { Height } \\
\text { (m) }\end{array}$ & $\begin{array}{l}\text { Offload } \\
\text { Cycle } \\
\text { Time } \\
\text { (hrs) }\end{array}$ & $\begin{array}{l}\text { Multiplier } \\
\text { for Drag } \\
\text { Rotor }\end{array}$ & $\begin{array}{l}\text { Multiplier } \\
\text { for Towe } \\
\text { Drag }\end{array}$ \\
\hline Nacelle & 57 & 90 & 33 & 0.8 & 0.8 & 0 & 80 & 1.5 & 6 & 0.5 & 1 & 0 \\
\hline Hub & 17 & 90 & 11.3 & 1.1 & 1.1 & 0 & 80 & 1 & 6 & 0.5 & 0 & 0 \\
\hline Blade 1 & 5.8 & 90 & 33.44 & 0.1 & 1.4 & 0 & 80 & 1 & 6 & 0.5 & 0.67 & 0 \\
\hline Blade 2 & 5.8 & 90 & 33.44 & 0.1 & 1.4 & 0 & 80 & 1 & 6 & 0.5 & 0.67 & 0 \\
\hline Blade 3 & 5.8 & 90 & 33.44 & 0.1 & 1.4 & 0 & 80 & 1 & 6 & 0.5 & 0.67 & 0 \\
\hline Tower Section 1 & 57.5 & 30 & 95.89 & 0.6 & 1.1 & 25 & 12 & 1 & 6 & 0.5 & 0 & 1 \\
\hline Tower Section 2 & 37.85 & 60 & 96.25 & 0.6 & 1.1 & 25 & 37 & 1 & 6 & 0.5 & 0 & 1 \\
\hline Tower Section 3 & 29.91 & 90 & 90 & 0.6 & 1.1 & 30 & 65 & 1 & 6 & 0.5 & 0 & 1 \\
\hline
\end{tabular}

These data are required for the ErectionCost and FoundationCost modules.

Table A-6. Sample Cable Specs Data

\begin{tabular}{lcccccc}
\hline $\begin{array}{l}\text { Array } \\
\text { Cable }\end{array}$ & $\begin{array}{l}\text { Current } \\
\text { Capacity } \\
\text { (A) }\end{array}$ & $\begin{array}{l}\text { Rated } \\
\text { Voltage } \\
(\mathbf{k V})\end{array}$ & $\begin{array}{l}\text { AC } \\
\text { Resistance } \\
\text { (Ohms/km) }\end{array}$ & $\begin{array}{l}\text { Inductance } \\
\text { (mH/km) }\end{array}$ & $\begin{array}{l}\text { Capacitance } \\
\text { (nF/km) }\end{array}$ & $\begin{array}{l}\text { Cost } \\
\text { (USD/linear } \\
\text { foot) }\end{array}$ \\
\hline AWG 1/0 & 300 & 36 & 0.253 & 0.398 & 0.179 & $\mathrm{X}$ \\
AWG 4/0 & 440 & 36 & 0.125 & 0.359 & 0.223 & $\mathrm{X}$ \\
MCM 500 & 640 & 36 & 0.061 & 0.317 & 0.293 & $\mathrm{X}$ \\
MCM 1000 & 830 & 36 & 0.037 & 0.291 & 0.375 & $\mathrm{X}$ \\
MCM 1250 & 935 & 36 & 0.029 & 0.284 & 0.411 & $\mathrm{X}$ \\
\hline
\end{tabular}

These data are required for the CollectionCost module.

$\mathrm{X}$ indicates proprietary input. $\mathrm{AWG}=$ American Wire Gauge, $\mathrm{MCM}=$ thousands of circular mils, $\mathrm{mH} / \mathrm{km}=$ millihenry per kilometer, and $\mathrm{nF} / \mathrm{km}=\mathrm{nanofarad}$ per kilometer. 
Table A-7. Sample Equipment Data

\begin{tabular}{lllc}
\hline Equipment ID & Operation & Equipment Name & Number of Equipment \\
\hline E1 & Base & $500 \mathrm{t}$ crawler & 1 \\
E1 & Base & $50 \mathrm{t}$ Truck crane & 1 \\
E1 & Top & $500 \mathrm{t}$ crawler & 1 \\
E1 & Top & $50 \mathrm{t}$ Truck crane & 2 \\
E2 & Top & $600 \mathrm{t}$ crawler & 1 \\
E2 & Top & $50 \mathrm{t}$ Truck crane & 2 \\
E2 & Top & $100 \mathrm{t}$ RT & 2 \\
E3 & Top & $750 \mathrm{t}$ crawler & 1 \\
E3 & Top & $100 \mathrm{t}$ RT & 2 \\
E4 & Top & $1,000 \mathrm{t}$ crawler & 1 \\
E4 & Top & $100 \mathrm{t}$ RT & 2 \\
ST1 & Top & $200 \mathrm{t}$ mobile & 1 \\
ST1 & Top & $100 \mathrm{t}$ RT & 2 \\
OL1 & Offload & $75 \mathrm{t}$ mobile & 2 \\
OL2 & Offload & $200 \mathrm{t}$ mobile & 2 \\
\hline
\end{tabular}

These data are required for the ErectionCost module.

Table A-8. Sample Data for Equipment Prices

\begin{tabular}{lccccc}
\hline $\begin{array}{l}\text { Equipment } \\
\text { Name }\end{array}$ & $\begin{array}{c}\text { Crane Capacity } \\
\text { (metric tons) }\end{array}$ & $\begin{array}{c}\text { Number of } \\
\text { Equipment }\end{array}$ & $\begin{array}{c}\text { Equipment Price } \\
\text { (USD/hr) }\end{array}$ & $\begin{array}{c}\text { Cost per Breakdown } \\
\text { (USD) }\end{array}$ & $\begin{array}{c}\text { Fuel Consumption } \\
\text { (gallons/day) }\end{array}$ \\
\hline Crawler crane & $\mathrm{X}$ & 1 & $\mathrm{X}$ & $\mathrm{X}$ & $\mathrm{X}$ \\
Truck crane & $\mathrm{X}$ & 1 & $\mathrm{X}$ & $\mathrm{X}$ & $\mathrm{X}$ \\
RT & $\mathrm{X}$ & 1 & $\mathrm{X}$ & $\mathrm{X}$ & $\mathrm{X}$ \\
Offload crane & $\mathrm{X}$ & 1 & $\mathrm{X}$ & $\mathrm{X}$ & $\mathrm{X}$ \\
\hline \multicolumn{5}{r}{}
\end{tabular}


Table A-9. Sample Input for Crane Specifications

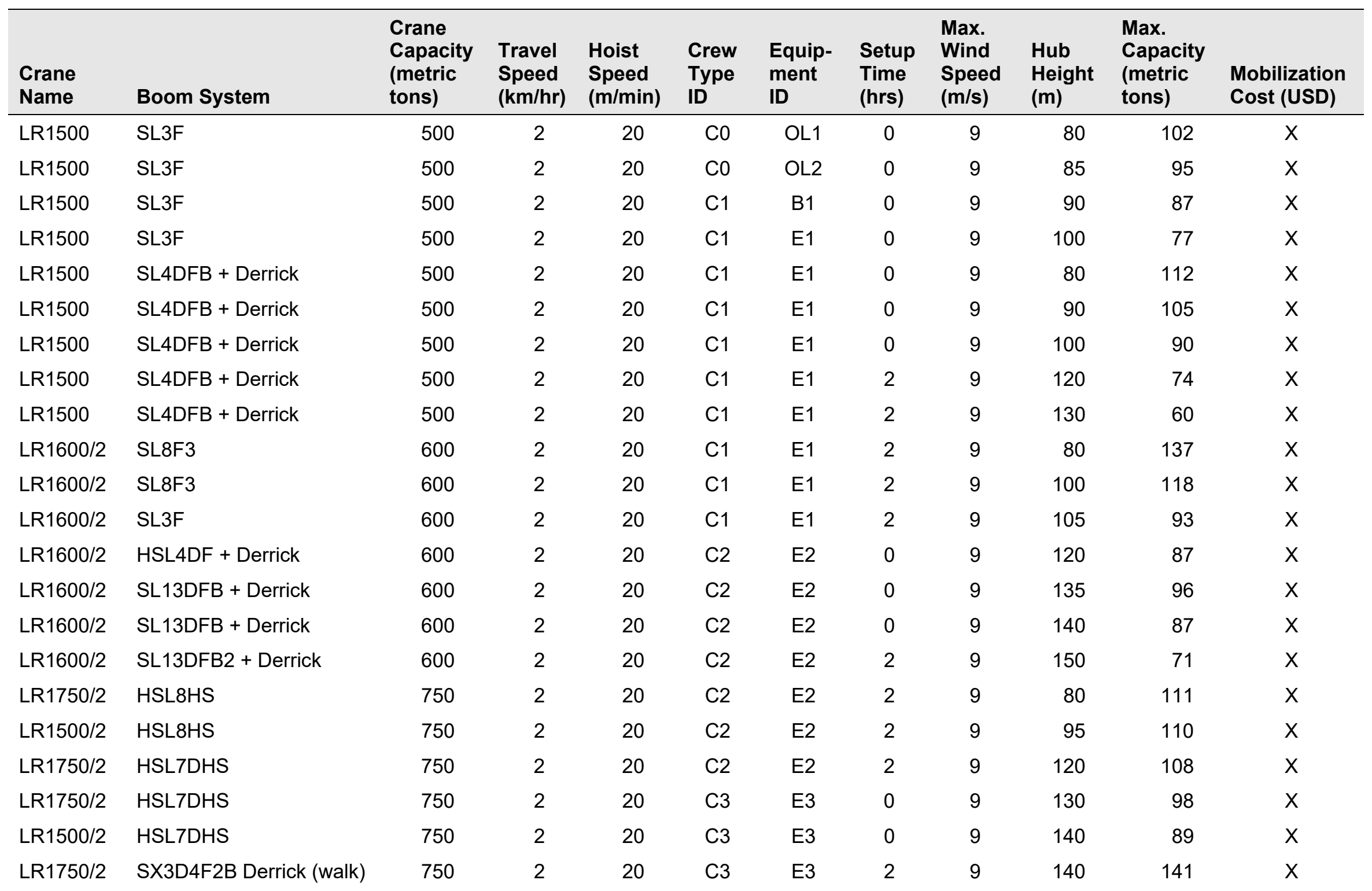




\begin{tabular}{|c|c|c|c|c|c|c|c|c|c|c|c|}
\hline $\begin{array}{l}\text { Crane } \\
\text { Name }\end{array}$ & Boom System & $\begin{array}{l}\text { Crane } \\
\text { Capacity } \\
\text { (metric } \\
\text { tons) }\end{array}$ & $\begin{array}{l}\text { Travel } \\
\text { Speed } \\
(\mathbf{k m} / \mathbf{h r})\end{array}$ & $\begin{array}{l}\text { Hoist } \\
\text { Speed } \\
(\mathrm{m} / \mathrm{min})\end{array}$ & $\begin{array}{l}\text { Crew } \\
\text { Type } \\
\text { ID }\end{array}$ & $\begin{array}{l}\text { Equip- } \\
\text { ment } \\
\text { ID }\end{array}$ & $\begin{array}{l}\text { Setup } \\
\text { Time } \\
\text { (hrs) }\end{array}$ & $\begin{array}{l}\text { Max. } \\
\text { Wind } \\
\text { Speed } \\
(\mathrm{m} / \mathrm{s})\end{array}$ & $\begin{array}{l}\text { Hub } \\
\text { Height } \\
\text { (m) }\end{array}$ & $\begin{array}{l}\text { Max. } \\
\text { Capacity } \\
\text { (metric } \\
\text { tons) }\end{array}$ & $\begin{array}{l}\text { Mobilization } \\
\text { Cost (USD) }\end{array}$ \\
\hline LR11000 & SL3F & 1,000 & 1 & 25 & $\mathrm{C} 3$ & E3 & 2 & 9 & 100 & 179 & $x$ \\
\hline LR11000 & SL3F & 1,000 & 1 & 25 & $\mathrm{C} 3$ & E3 & 0 & 9 & 110 & 152 & $x$ \\
\hline LR11000 & SL2DFB & 1,000 & 1 & 25 & $\mathrm{C} 4$ & E4 & 3 & 9 & 150 & 154 & $x$ \\
\hline LR11000 & SL2DFB & 1,000 & 1 & 25 & $\mathrm{C} 4$ & E4 & 3 & 9 & 155 & 140 & $x$ \\
\hline LR11000 & SL2DFB & 1,000 & 1 & 25 & $\mathrm{C} 4$ & E4 & 3 & 9 & 160 & 120 & $x$ \\
\hline LR11000 & SL2DFB & 1,000 & 1 & 25 & $\mathrm{C} 4$ & E4 & 3 & 9 & 180 & 73 & $x$ \\
\hline
\end{tabular}

Liebherr-Werk Ehingen GmbH 2018 (11) and industry data

$\mathrm{X}$ indicates proprietary input and these data are required for the ErectionCost module. 
Table A-10. Sample Data for Crew

\begin{tabular}{|c|c|c|c|c|}
\hline Crew Type ID & Operation & Crew Name & Labor Type ID & Number of Workers \\
\hline MO & Management & Management - project size & Project manager & 1 \\
\hline MO & Management & Management - project size & Site manager & 1 \\
\hline MO & Management & Management - project size & Construction manager & 1 \\
\hline MO & Management & Management - project size & Project engineer & 1 \\
\hline MO & Management & Management - project size & Safety or QC manager & 1 \\
\hline MO & Management & Management - project size & Logistics manager & 1 \\
\hline MO & Management & Management - project size & Office admin & 1 \\
\hline M1 & Management & Management - rate construction & Tool room & 1 \\
\hline M1 & Management & Management - rate construction & Electrician & 2 \\
\hline MCO & Mechanical completion & Mechanical completion & QC/QA tech & 2 \\
\hline MCO & Mechanical completion & Mechanical completion & Electrician & 1 \\
\hline $\mathrm{CO}$ & Offload & Offload can tower & Crane operator & 2 \\
\hline $\mathrm{CO}$ & Offload & Offload can tower & Oiler & 2 \\
\hline $\mathrm{CO}$ & Offload & Offload can tower & Iron worker & 3 \\
\hline $\mathrm{CO}$ & Offload & Offload can tower & Rigger foreman & 1 \\
\hline C5 & Base & Base 300t & Crane operator & 2 \\
\hline C5 & Base & Base 300t & Oiler & 2 \\
\hline C5 & Base & Base 300t & Iron worker & 3 \\
\hline C5 & Base & Base 300t & Truck driver & 1 \\
\hline C5 & Base & Base 300t & Rigger foreman & 1 \\
\hline C6 & Base & Base 400t & Crane operator & 2 \\
\hline C6 & Base & Base 400t & Oiler & 2 \\
\hline C6 & Base & Base 400t & Iron worker & 3 \\
\hline C6 & Base & Base 400t & Truck driver & 1 \\
\hline
\end{tabular}




\begin{tabular}{|c|c|c|c|c|}
\hline Crew Type ID & Operation & Crew Name & Labor Type ID & Number of Workers \\
\hline $\mathrm{C} 6$ & Base & Base $400 t$ & Rigger foreman & 1 \\
\hline $\mathrm{C} 1$ & Base & Base $500 t$ & Crane operator & 2 \\
\hline $\mathrm{C} 1$ & Base & Base $500 t$ & Oiler & 2 \\
\hline $\mathrm{C} 1$ & Base & Base $500 t$ & Iron worker & 3 \\
\hline $\mathrm{C} 1$ & Base & Base $500 t$ & Truck driver & 1 \\
\hline $\mathrm{C} 1$ & Base & Base $500 t$ & Rigger foreman & 1 \\
\hline $\mathrm{C7}$ & Top & Top 400t & Crane operator & 2 \\
\hline $\mathrm{C7}$ & Top & Top 400t & Oiler & 2 \\
\hline $\mathrm{C} 7$ & Top & Top 400t & Iron worker & 6 \\
\hline $\mathrm{C7}$ & Top & Top 400t & Truck driver & 1 \\
\hline $\mathrm{C} 7$ & Top & Top 400t & Rigger foreman & 1 \\
\hline $\mathrm{C} 1$ & Top & Top 500t & Crane operator & 2 \\
\hline $\mathrm{C} 1$ & Top & Top 500t & Oiler & 2 \\
\hline $\mathrm{C} 1$ & Top & Top 500t & Iron worker & 6 \\
\hline $\mathrm{C} 1$ & Top & Top 500t & Truck driver & 1 \\
\hline $\mathrm{C} 1$ & Top & Top 500t & Rigger foreman & 1 \\
\hline $\mathrm{C} 2$ & Top & Top 600t & Crane operator & 2 \\
\hline $\mathrm{C} 2$ & Top & Top 600t & Oiler & 2 \\
\hline $\mathrm{C} 2$ & Top & Top 600t & Iron worker & 6 \\
\hline $\mathrm{C} 2$ & Top & Top 600t & Truck driver & 1 \\
\hline $\mathrm{C} 2$ & Top & Top 600t & Rigger foreman & 1 \\
\hline $\mathrm{C} 3$ & Top & Top 750t & Crane operator & 2 \\
\hline C3 & Top & Top 750t & Oiler & 2 \\
\hline $\mathrm{C} 3$ & Top & Top 750t & Iron worker & 6 \\
\hline C3 & Top & Top 750t & Truck driver & 1 \\
\hline
\end{tabular}




\begin{tabular}{llllc}
\hline Crew Type ID & Operation & Crew Name & Labor Type ID & Number of Workers \\
\hline C3 & Top & Top 750t & Rigger foreman & 1 \\
C4 & Top & Top 1,000t & Crane operator & 2 \\
C4 & Top & Top 1,000t & Oiler & 2 \\
C4 & Top & Top 1,000t & Iron worker & 6 \\
C4 & Top & Top 1,000t & Truck driver & 1 \\
C4 & Top & Top 1,000t & Rigger foreman & 1 \\
\hline
\end{tabular}

Table A-11. Sample Price Data for Crew

\begin{tabular}{lcc}
\hline Labor Type ID & Hourly Rate (USD/hr) & Per Diem (USD/day) \\
\hline Crane operator & $\mathrm{X}$ & $\mathrm{X}$ \\
Oiler & $\mathrm{X}$ & $\mathrm{X}$ \\
Rigger & $\mathrm{X}$ & $\mathrm{X}$ \\
Truck driver & $\mathrm{X}$ & $\mathrm{X}$ \\
Iron worker & $\mathrm{X}$ & $\mathrm{X}$ \\
Project manager & $\mathrm{X}$ & $\mathrm{X}$ \\
Site manager & $\mathrm{X}$ & $\mathrm{X}$ \\
Construction manager & $\mathrm{X}$ & $\mathrm{X}$ \\
Project engineer & $\mathrm{X}$ & $\mathrm{X}$ \\
Safety or QC manager & $\mathrm{X}$ & $\mathrm{X}$ \\
Logistics manager & $\mathrm{X}$ & $\mathrm{X}$ \\
Rigger foreman & $\mathrm{X}$ & $\mathrm{X}$ \\
Rigger & $\mathrm{X}$ & $\mathrm{X}$ \\
Operator & $\mathrm{X}$ & $\mathrm{X}$ \\
Oiler & $\mathrm{X}$ & $\mathrm{X}$ \\
Electrician & $\mathrm{X}$ & $\mathrm{X}$ \\
\hline
\end{tabular}

$\mathrm{X}$ indicates proprietary input. 
Table A-12. Sample Data for Material Prices

\begin{tabular}{llc}
\hline Material Type ID & Unit & USD per Unit \\
\hline Concrete $3000 \mathrm{psi}$ & cubic yard & $\mathrm{X}$ \\
Concrete $5000 \mathrm{psi}$ & cubic yard & $\mathrm{X}$ \\
Concrete 8000 & cubic yard & $\mathrm{X}$ \\
Steel-rebar & ton (short) & $\mathrm{X}$ \\
$3 / 4 "$ crushed stone & LCY & $\mathrm{X}$ \\
Excavated dirt & cubic yard & 0 \\
Backfill & cubic yard & 0 \\
\hline
\end{tabular}

$\mathrm{X}$ indicates proprietary input.

Table A-13. Sample Data for RSMeans

\begin{tabular}{|c|c|c|c|c|c|}
\hline Operation ID & Type of Cost & Material Type ID & Rate (USD/ Unit) & Units & Daily Output \\
\hline Topsoil stripping and stockpiling & Labor & & $x$ & cubic yard & $x$ \\
\hline Compaction of soil (subgrade and crane path) & Labor & & $\mathrm{X}$ & ECY & $x$ \\
\hline Placing road base (hauling) & Labor & $3 / 4 "$ crushed stone & $x$ & LCY & $x$ \\
\hline Rough grading road base & Labor & & & $100,000 \mathrm{ft}^{2}$ & \\
\hline Compacting road base & Labor & & $x$ & LCY & $x$ \\
\hline Topsoil stripping and stockpiling & Equipment rental & & $x$ & cubic yard & $x$ \\
\hline Compaction of soil (subgrade and crane path) & Equipment rental & & $\mathrm{x}$ & ECY & $x$ \\
\hline Placing road base (hauling) & Equipment rental & $3 / 4 "$ crushed stone & $x$ & LCY & $x$ \\
\hline Rough grading road base & Equipment rental & & $x$ & $100,000 \mathrm{ft}^{2}$ & $x$ \\
\hline Compacting road base & Equipment rental & & $x$ & LCY & $x$ \\
\hline
\end{tabular}

$\mathrm{X}$ indicates proprietary input. 
Table A-14. Site Facility Building Area Defaults as Function of Project Size

\begin{tabular}{ccc}
\hline Size Minimum (MW) & Size Maximum (MW) & Building Area (sq. ft.) \\
\hline 0 & 200 & 3,000 \\
200 & 500 & 5,000 \\
800 & 1,000 & 9,000 \\
1,000 & 5,000 & 12,000 \\
\hline
\end{tabular}

\section{A.3 Hard-Coded Values}

In addition to the input data listed above, the model contains several hard-coded values, including road properties (Table A-15) and parameters used in the ManagementCost module (Table A-16). These values can be changed by the user, but they must be modified within the code rather than in the input data.

Table A-15. Road Properties

\begin{tabular}{lc}
\hline Property & Default Value (m) \\
Road width & 6.1 \\
Crane width & 11 \\
Depth to subgrade & 0.1 \\
Thickness & 0.2 \\
Lift depth & 0.2 \\
\hline
\end{tabular}


Table A-16. Defaults Used in ManagementCost Module

\begin{tabular}{llr}
\hline Parameter Name & Units & Value \\
\hline Number of highway permits & $\mathrm{n} / \mathrm{a}$ & 10 \\
Number of access roads & $\mathrm{n} / \mathrm{a}$ & 2 \\
Markup contingency & $\%$ & 0.03 \\
Markup warranty management & multiplier & 0.0002 \\
Markup sales and use tax & multiplier & 0 \\
Markup overhead & multiplier & 0.05 \\
Markup profit margin & multiplier & 0.05 \\
\hline
\end{tabular}

\section{A.4 Inputs and Outputs by Module Type}

Tables A-17 through A-24 list the inputs and outputs for each of the modules. These inputs and outputs populate the input and output dictionaries shown in the software architecture diagram (Figure 9).

Table A-17. Inputs and Outputs in CollectionCost Module

\begin{tabular}{ll}
\hline Inputs & Outputs \\
\hline project_name & max_turb_per_cable \\
ac_resistance & num_turb_per_cable \\
cable_power & turb_section_length \\
capacitance & total_cable_len_km \\
char_impedance & total_turb_per_string \\
current_capacity & num_full_strings \\
inductance & num_leftover_turb \\
line_frequency_hz & num_partial_strings \\
power_factor & perc_partial_string \\
rated_voltage & num_strings \\
downstream_connection & trench_len_to_substation_km
\end{tabular}




\begin{tabular}{|c|c|}
\hline Inputs & Outputs \\
\hline turb_sequence & cable_len_to_substation_km \\
\hline rsmeans (dataframe) & trench_length_km \\
\hline crew_cost & management_crew (dataframe) \\
\hline crew & operation_data_entire_farm (dataframe) \\
\hline construction_duration & wind_delays \\
\hline time_construct & wind_delay_time \\
\hline hour_day & time_construct_days \\
\hline user_defined_home_run_trench & wind_multiplier \\
\hline trench_len_to_substation_km & operation_data_id_days_crews_workers (dataframe) \\
\hline plant_capacity_MW & operation_data_entire_farm (dataframe) \\
\hline row_spacing_rotor_diameters & total_collection_cost (dataframe) \\
\hline \multicolumn{2}{|l|}{ upstream_turb } \\
\hline \multicolumn{2}{|l|}{ turbine_spacing_rotor_diameters } \\
\hline \multicolumn{2}{|l|}{ rotor_diameter_m } \\
\hline \multicolumn{2}{|l|}{ overtime_multiplier } \\
\hline \multicolumn{2}{|l|}{ weather_window } \\
\hline \multicolumn{2}{|l|}{ start_delay_hours } \\
\hline \multicolumn{2}{|l|}{ mission_time_hours } \\
\hline \multicolumn{2}{|l|}{ critical_wind_speed_m_per_s } \\
\hline \multicolumn{2}{|l|}{ wind_height_of_interest_m } \\
\hline \multicolumn{2}{|l|}{ wind_shear_exponent } \\
\hline \multicolumn{2}{|l|}{ time_construct } \\
\hline \multicolumn{2}{|l|}{ hour_day } \\
\hline per_diem_rate & \\
\hline
\end{tabular}


Table A-18. Inputs and Outputs in FoundationCost Module

\begin{tabular}{ll}
\hline Inputs & Outputs \\
\hline project_name & F_dead_kN_per_turbine \\
depth & F_horiz_kN_per_turbine \\
rated_thrust_N & M_tot_kN_m_per_turbine \\
bearing_pressure_n_m2 & Radius_s_m \\
gust_velocity_m_per_s & Radius_b_m \\
component_data (dataframe) & Radius_m \\
num_turbines & foundation_volume_m3_per_turbine \\
overtime_multiplier & material_needs_per_turbine (dataframe) \\
material_price (dataframe) & material_needs_entire_farm (dataframe) \\
rsmeans (dataframe) & operation_data_id_days_crews_workers (dataframe) \\
weather_window & operation_data_entire_farm (dataframe) \\
start_delay_hours & labor_equip_data (dataframe) \\
mission_time_hours & total_foundation_cost (dataframe) \\
critical_wind_speed_m_per_s & \\
wind_height_of_interest_m & \\
wind_shear_exponent & \\
time_construct & \\
hour_day & \\
per_diem_rate &
\end{tabular}


Table A-19. Inputs and Outputs in SitePreparationCost Module

\begin{tabular}{|c|c|}
\hline Inputs & Outputs \\
\hline project_name & road_length_m \\
\hline road_width_ft & road_volume_m3 \\
\hline road_thickness & depth_to_subgrade_m \\
\hline crane_width & material_volume_cubic_yards \\
\hline num_access_roads & topsoil_volume \\
\hline rotor_diameter_m & embankment_volume_crane \\
\hline turbine_spacing_rotor_diameters & embankment_volume_road \\
\hline num_turbines & rough_grading_area \\
\hline overtime_multiplier & material_needs (dataframe) \\
\hline material_price (dataframe) & operation_data (dataframe) \\
\hline rsmeans (dataframe) & total_road_cost (dataframe) \\
\hline \multicolumn{2}{|l|}{ weather_window } \\
\hline \multicolumn{2}{|l|}{ start_delay_hours } \\
\hline \multicolumn{2}{|l|}{ mission_time_hours } \\
\hline \multicolumn{2}{|l|}{ critical_wind_speed_m_per_s } \\
\hline \multicolumn{2}{|l|}{ wind_height_of_interest_m } \\
\hline \multicolumn{2}{|l|}{ wind_shear_exponent } \\
\hline \multicolumn{2}{|l|}{ time_construct } \\
\hline \multicolumn{2}{|l|}{ hour_day } \\
\hline per_diem_rate & \\
\hline
\end{tabular}


Table A-20. Inputs and Outputs in SubstationCost Module

\begin{tabular}{ll}
\hline Inputs & Outputs \\
\hline project_name & \\
distance_to_interconnect_mi & total_substation_cost (dataframe) \\
project_size & \\
\hline
\end{tabular}

Table A-21. Inputs and Outputs in GridConnectionCost Module

\begin{tabular}{ll}
\hline Inputs & Outputs \\
\hline project_name & interconnect_adder_USD \\
distance_to_interconnect_mi & total_transdict_cost (dataframe) \\
interconnect_voltage_kV & \\
new_switchyard & \\
\hline
\end{tabular}


Table A-22. Inputs and Outputs in ErectionCost Module

\begin{tabular}{ll}
\hline Inputs & Outputs \\
\hline project_specs (dataframe) & component_name_topvbase (dataframe) \\
crane_specs (dataframe) & possible_cranes (dataframe) \\
crew (dataframe) & operation_time (dataframe) \\
crew_price (dataframe) & offload_specs (dataframe) \\
equip (dataframe) & offload_time \\
equip_price (dataframe) & crane_specs_withoffload (dataframe) \\
component_specs (dataframe) & operation_time_withoffload (dataframe) \\
rate_of_deliveries & enhanced_crane_specs (dataframe) \\
weather_window & separate_basetop (dataframe) \\
wind_shear_exponent & same_basetop (dataframe) \\
overtime_multiplier & crew_cost (dataframe) \\
allow_same_flag & erection_cost_output (dataframe) \\
time_construct & erection_wind_mult \\
hour_day & crane_choice (dataframe) \\
& crane_data_output (dataframe) \\
& crane_cost_details (dataframe) \\
& total_cost_summed_erection \\
& management_crews (dataframe) \\
& management_crews_grouped (dataframe) \\
& \\
\hline &
\end{tabular}


Table A-23. Inputs and Outputs in ManagementCost Module

\begin{tabular}{ll}
\hline Inputs & Outputs \\
\hline project_value_usd & insurance \\
foundation_cost_usd & construction_permitting \\
construction_time_months & project_management \\
num_hwy_permits & bonding \\
num_turbines & engineering_foundations_and_collection_sys \\
project_size_megawatts & site_security \\
hub_height_meters & met_mast \\
num_access_roads & site_facility \\
markup_contingency & markup_contingency \\
markup_warranty_management & total_cost \\
markup_sales_anduse_tax & \\
markup_overhead & \\
markup_profit_margin & \\
site_facility_building_area_df (dataframe) &
\end{tabular}

Table A-24. Inputs and Outputs in WeatherDelay Module

\begin{tabular}{ll}
\hline Inputs & Outputs \\
\hline weather_window & wind_delay \\
start_delay_hours & \\
mission_time_hours & \\
critical_wind_speed_m_per_s & \\
wind_height_of_interest_m & \\
wind_shear_exponent & \\
\hline
\end{tabular}

